\title{
Article \\ Experimental and Numerical Peeling Investigation on Aged Multi-Layer Anti-Shatter Safety Films (ASFs) for Structural Glass Retrofit
}

\author{
Silvana Mattei (D), Luca Cozzarini (D) and Chiara Bedon * (D) \\ Department of Engineering and Architecture, University of Trieste, 34127 Trieste, Italy; \\ silvana.mattei@phd.units.it (S.M.); lcozzarini@units.it (L.C.) \\ * Correspondence: chiara.bedon@dia.units.it; Tel.: +39-04-0558-3837
}

check for updates

Citation: Mattei, S.; Cozzarini, L.; Bedon, C. Experimental and Numerical Peeling Investigation on Aged Multi-Layer Anti-Shatter Safety Films (ASFs) for Structural Glass Retrofit. Symmetry 2022, 14, 162. https://doi.org/10.3390/sym14010162

Academic Editor: Jan Awrejcewicz

Received: 15 December 2021

Accepted: 11 January 2022

Published: 14 January 2022

Publisher's Note: MDPI stays neutral with regard to jurisdictional claims in published maps and institutional affiliations.

Copyright: (c) 2022 by the authors Licensee MDPI, Basel, Switzerland. This article is an open access article distributed under the terms and conditions of the Creative Commons Attribution (CC BY) license (https:// creativecommons.org/licenses/by/ $4.0 /)$.

\begin{abstract}
Anti-shatter safety films (ASFs) are often used for structural glass applications. The goal is to improve the response of monolithic elements and prevent fragments from shattering. Thus, the main reason behind their use is the possibility to upgrade safety levels against the brittle failure of glass and minimize the number of possible injuries. However, the impact response of glass elements bonded with Polyethylene terephthalate (PET)-films and pressure sensitive adhesives (PSAs) still represents a research topic of open discussion. Major challenges derive from material characterization and asymmetrical variability under design loads and ageing. In particular, the measurement of interface mechanical characteristics for the adhesive layer in contact with glass is a primary parameter for the ASF choice optimization. For this reason, the present paper presents an experimental campaign aimed at calibrating some basic mechanical parameters that provide the characterization of constitutive models, such as tensile properties (yielding stress and Young modulus) for PET-film and adhesive properties for PSA (energy fracture and peel force). In doing so, both tensile tests for PET-films and peeling specimens are taken into account for a commercially available ASF, given that the peeling test protocol is one of most common methods for the definition of adhesion properties. Moreover, an extensive calibration of the Finite Element (FE) model is performed in order to conduct a parametric numerical analysis of ASF bonded glass solutions. Furthermore, a Kinloch approach typically used to determine the fracture energy of a given tape by considering a variable peel angle, is also adopted to compare the outcomes of calibration analyses and FE investigations on the tested specimens. Finally, a study of the effect of multiple aspects is also presented. The results of the experimental program and the following considerations confirm the rate dependence and ageing dependence in peel tests.
\end{abstract}

Keywords: anti-shatter safety films (ASFs); structural glass; adhesion; ageing; experiments; finite element (FE) numerical models

\section{Introduction}

Polyethylene terephthalate (PET) is a semi-crystalline thermoplastic polymer with a high performance in terms of strength, stability, electrical properties, and the ability to resist ultraviolet (UV) light, also known as UV resistance. Furthermore, this material is fully recyclable and can be used for a broad range of applications with a long service life. Generally, plastic materials such as PET, polyethylene (PE), polyvinyl chloride (PVC) or polypropylene (PP) are used in the form of extensible or inextensible films for food packaging [1], trash bags [2], printed films, plastic cards, geomembranes, etc. Despite their high cost, the choice of PET-film solutions as protective layers for the retrofit of structural glass panels is typically suggested by strength quality and delamination properties. Moreover, tape manufactures usually take advantage of pressure sensitive adhesives (or PSAs) on their tape, which require slight pressure to adhere to most clean and dry surfaces. Anti-shatter safety films (ASFs) are thus a representative of the widespread application of PSAs, and their specific use for glass elements is rather common in civil engineering. These films can 
in fact be used for a multitude of applications, including to reduce transparency, obscure and improve the transmittance characteristics, or enhance safety levels against fracture.

It is, in fact, known that the majority of casualties caused by a sudden extreme event, of natural or anthropic origin, occur not due to structural collapse [3,4], but to falling rubble, tiles and glass fragments and shards $[5,6]$. This suggests that special attention should be paid not only to the (target) primary structure as a whole, but also to secondary components. The use of PET-films, in this regard, is known to reduce the possibility of flying glass debris following accidental actions of any nature, especially those of impulsive and unpredictable origin. For this reason, in addition to the multitude of efforts that have been made to improve energy saving features, various experimental studies have shown in the past that the use of protective films can increase the post-fracture residual performance of damaged ordinary glass elements. Many laboratory studies have been conducted to understand how the use of these films on glass members can affect the expected strength under impact [7]. A ball-drop experimental program is presented in [8] for traditional glass windows. The use of protective films proved to offer increased safety levels to window elements, and thus reduce the potential risk for occupants. Several authors have studied ways to improve the performance of structural glass based on thin films [9]. Brueggeman et al. [10] proposed an insulation system of panels to prevent damage. Other research studies have been dedicated to the detection of efficient methods for avoiding severe consequences for customers, that is using PET-films applied on both sides of glass panels [11] or on the external surface only [12-14]. Memari et al. [14] explored the influence of films using a Racking Test Facility. The experiments demonstrated a greater strength for film-bonded glass elements, in addition to a limited ability to create flying debris, compared to ordinary glass members. On the other hand, literature efforts are still rather limited towards the generalized quantification of advantages in using similar protective films, as well as towards the definition of basic mechanical properties. In this regard, it is worth to note that a major issue regarding the performance of ASFs is that the quality of mechanical properties at the interface is affected by many factors, such as intrinsic material properties, composition, processing method and operational conditions [15].

The present investigation studies how the influence of temperature and ageing time can influence the characteristics of basic material components, by taking into account a commercial multi-layer ASF product. The aim is to provide a complete characterization of the adhesive layer in direct contact with glass, by using a combination of experimental tests, theoretical assessment methods and Finite Element (FE) numerical parametric studies. This is achieved with peel adhesion testing methods, which is a traditional technique that can be used for assessing the characteristics of ASFs, as well as the effectiveness of aged ASFs [15].

\section{Background of Peeling Mechanics and Current Approach}

Adhesion is an extremely complex process that concerns the creation and toughness of the bonding that can take place between any two materials. In general, two surfaces attract when the separation between them is within the range of interatomic distance: the surfaces are in contact with the intermolecular interaction forces of van der Waals. Among the many factors affecting adhesive properties, the three most important are: the viscoelasticity of the materials in contact, the surface roughness and the contact geometry.

In this paper, attention is focused on the study of the adhesion between a polymeric surface and a glass substrate. Adhesive properties are thus measured by peel testing, and the approach is suitable, especially when considering weak adhesion, as the deformation in the peel arm can be accounted for as elastic. To this aim, the mechanical relations of the peeling test are firstly introduced by following the theoretical and experimental evolution of the method from the mechanical point of view. Kinloch's analysis is then addressed by describing in its essential points the energy balance on the peeling mechanics.

In the 1950's, Gent was the first to propose a study on the peeling of an adhesive polymer from a surface with a constant peel angle [16]. Later, Kaelble analysed the bond 
behaviour by introducing the role of microfracture mechanisms in the process [17-19]. The study showed how peel rate and temperature can affect the failure at the interface for an adhesive system [20]. In particular, Kaeble provided a complex expression for the calculation of peel force depending on the mechanical and rheological properties of the adhesive layer, and as a function of normal and shear stresses at the peel tip position. Furthermore, Gent and Petrich [21] built a peeling model from a rigid substrate, in which the calculation of peel strength depended on parameters such as the thickness of the adhesive, the critical elongation to break or detach from the fibrillae, and efforts in fibrillae. The stronger the adhesive, the cavitation process and adhesive fibrillation develops during the test. The introduction of viscoelastic behaviour from the thin films resulted in the definition of the two transitions observed in similar materials, depending on the separation speed: the liquid-like delamination process was impacted by viscoelastic effects due to the deformation rate and adhesive stress-strain curve, which was rubber-like, associated with the transition of the elastomer adhesive to glass.

The peel test of flexible laminates as a fracture mechanics problem was introduced by Kinloch et al. [22,23]. Fracture mechanics is based on the basic assumption of continuous mechanics, thus the details of the molecular structure of the polymer are ignored and the subject of the study is seen as a single element with specific physical properties [24].

According to the aforementioned approach, this energy-balance approach shows that the external work carried out by the peel force $\left(U_{e x t}\right)$ is the sum of the energy of creating a surface $\left(G_{a}\left[\mathrm{~J} / \mathrm{m}^{2}\right]\right)$, the energy of extending the peel arm $\left(U_{s}+U_{d t}\right)$ and the energy of bending the peel arm $\left(U_{d b}\right)[22]$ :

$$
G_{a}=\frac{1}{b}\left(\frac{d U_{e x t}}{d a}-\frac{d U_{s}}{d a}-\frac{d U_{d t}}{d a}-\frac{d U_{d b}}{d a}\right)
$$

where $b$ represents the width of the tape and $a$ corresponds to the surface involved in the delamination process.

Generally, the measured peel force $P$ is significantly dependent on geometry setup (peel angle, speed and laminated structure). As seen in the study by Kinloch, the total energy input for a single-arm peel test can be calculated as a function of peel strength $P, b$ and the peel angle as in Equation (2), where the peel arm is considered inextensible [22]:

$$
G_{a}^{\infty E}=\frac{P}{b}(1-\cos \theta)
$$

However, there are no quantities in Equation (2) which can be attributed to the mechanical properties of the material, adhesive, or to the thickness of the strip. This limit depends on the simplified hypothesis of perfectly rigid in tension and completely flexible in bending tape, and therefore the external work is simply transferred to the surface at the separation point. On the contrary, by considering the tensile deformation of the tape, it is found that [22]:

$$
G_{c}^{e b}=\frac{P}{b}\left(1+\varepsilon_{a}-\cos \theta\right)-h_{s} \int_{0}^{\varepsilon_{a}} \sigma d \varepsilon
$$

where $h_{S}$ is the thickness of the peel arm and $\sigma$ is the stress due to peel force which causes an elongation $\varepsilon_{a}$. This results in an increase in travel distance of the peel force, which becomes $\left(1+\varepsilon_{a}-\cos \theta\right) a$.

Moreover, the tape that is delaminated during the test (i.e., near the point of contact), is subjected to strong bending, particularly for a $90^{\circ}$ peel test. This bending involves a loss of local energy that should be properly taken into account, so as to avoid the risk of erroneously higher measured values for $G_{c}$. Thus, if plastic or viscoelastic bending of the peeling arm is taken into account [22]:

$$
G_{c}=G_{c}^{e b}-\frac{d U_{d b}}{d a}=G_{c}^{e b}-G_{d b}
$$


where the contribution $G_{d b}$ denotes the total energy loss in the loading and unloading cycle per unit area.

Since the geometries of the case study are different from the issue discussed by Kinloch, a revised approach that can calculate each increment of energy based on the above formulation (Equations (1)-(4)) and take into account the variability of peel angle is needed.

In the present work, a discretization of the problem is in fact conducted with a variable

$\theta$. For each time step of data acquisition an addendum of summation, for Equations (2) and (3), respectively, it can be calculated by:

$$
\begin{gathered}
\frac{1}{b}\left[\frac{f_{i+1}}{\sin \theta_{i+1}}\left(1-\cos \theta_{i+1}\right)-\frac{f_{i}}{\sin \theta_{i}}\left(1-\cos \theta_{i}\right)\right] \\
\frac{1}{b}\left[\frac{f_{i+1}}{\sin \theta_{i+1}}\left(1+\varepsilon_{a(i+1)}-\cos \theta_{i+1}\right)-\frac{f_{i}}{\sin \theta_{i}}\left(1+\varepsilon_{a i}-\cos \theta_{i}\right)\right]-h_{s} E \frac{\varepsilon_{a}^{2}}{2}
\end{gathered}
$$

It is worth noting that Equation (6) is valid in case of film with linear tensile deformation only (i.e., $\varepsilon_{a}<\varepsilon_{y}$ ). Due to the low force values applied during the peeling test, this is in fact what generally happens.

The final required term, $G_{d b}$, cannot be evaluated through a simple summation, due to the assumed methodology to derive it. Thus, to obtain a consistent value of adhesion energy, which can be successively calibrated through FE numerical procedures, a mean of the peel angle is considered in order to apply the equations proposed in [25], based on the elastic-plastic behaviour of the peeling arm modelled as a bilinear, work-hardening material $\left(E_{2}=\alpha E\right)$.

The adopted method consists of an iteration that accounts for the different loading states, as reported in [22], that is:

- Case \#1-Elastic deformation during bending loading and unloading:

$$
\begin{gathered}
\frac{G_{d b}}{G_{\text {max }}^{e}}=0 \\
\frac{G_{a}^{\infty E}}{G_{\max }^{e}}=\frac{1-\cos \theta}{1-\cos \left(\theta-\theta_{0}\right)} \frac{k_{0}^{2}}{3}
\end{gathered}
$$

- Case \#2-Plastic deformation during bending loading and elastic deformation during bending unloading:

$$
\begin{gathered}
\frac{G_{d b}}{G_{\max }^{e}}=(1-\alpha)\left[\frac{k_{0}^{2}}{3}+\frac{2(1-\alpha)^{2}}{3 k_{0}}-1\right] \\
\frac{G_{a}^{\infty E}}{G_{\text {max }}^{e}}=\frac{1-\cos \theta}{1-\cos \left(\theta-\theta_{0}\right)} \frac{k_{0}^{2}}{3}
\end{gathered}
$$

- Case \#3-Plastic deformation during bending loading and unloading:

$$
\begin{gathered}
\frac{G_{d b}}{G_{\text {max }}^{e}}=f_{1}\left(k_{0}\right) \\
\frac{G_{a}^{\infty E}}{G_{\text {max }}^{e}}=\frac{1-\cos \theta}{1-\cos \left(\theta-\theta_{0}\right)} f_{2}\left(k_{0}\right)
\end{gathered}
$$

where $k_{0}$ represents the rate between $R_{1}$, the radius of curvature related to the initial yielding of peeling arm, and $R_{0}$, the actual radius of the curvature at the peel tip position. Furthermore, $f_{1}$ and $f_{2}$ are a function of $k_{0}$ and the work-hardening parameter $\alpha$ according to the Kinloch method [22].

The parameter $\theta_{0}$ (named root rotation) in the aforementioned expressions is herein introduced to denote a local angle and is thus substantially different from the imposed 
angle $\theta$, which represents the rotation of the "beam" representing the peel arm. The limit condition $\theta_{0}=\theta$, in this regard, means that the peel arm has zero bending stiffness and acts as a string.

Although "Case \#3" is generally the best representative of the loading and unloading of the peeling arm, "Case \#1" represents more precisely the actual material behaviour for the polymeric materials involved in the present investigation.

Recently, IC-Peel software [26] was provided by Imperial College in order to automate the necessary calculations by the numerical integration of the bilinear fit of the experimental material curve $\sigma-\varepsilon$ (i.e., Young Modulus $E$, in GPa, thickness $h_{s}$, in $\mathrm{mm}$, and yielding stress $\sigma_{y}$ ) and peel test geometry. As a benchmark for the present methodology, the aforementioned tool is herein employed, and a comparison of results is summarized in Figure 1. In particular, the effects of the test rate $(v)$ and ageing conditions were considered relevant in the assessment of the adhesive behaviour, as several studies confirmed their influence. As explained in Section 6.2, the different scenarios of ageing were chosen after $T_{g}$ (glass transition temperature) was identified by preliminary material investigations and within the general range of temperatures that glass is exposed to in buildings. It is worth noting the rather close correlation of calculated values, namely in the form of a rather small percentage variation in the proposed comparative charts.

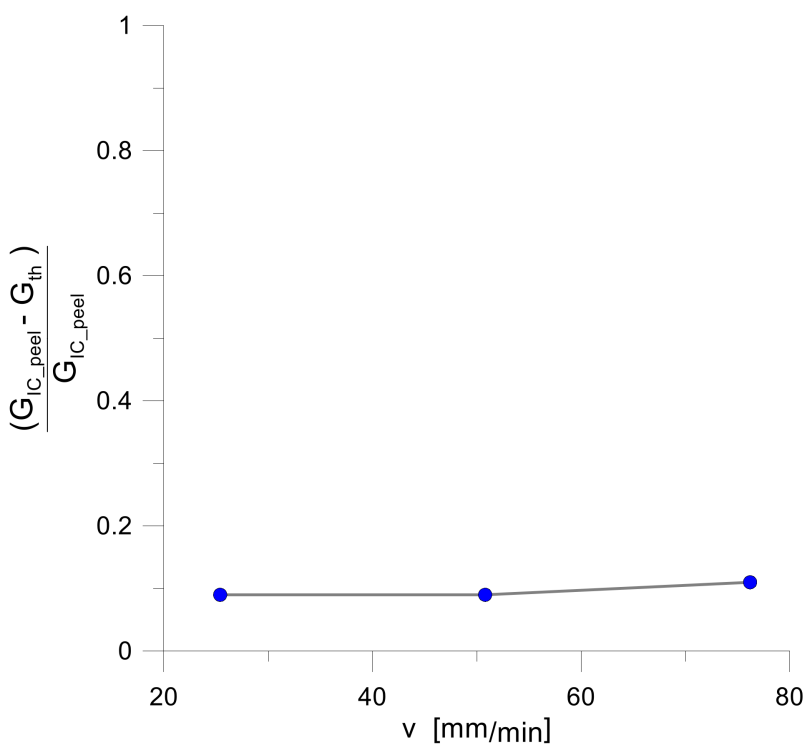

(a)

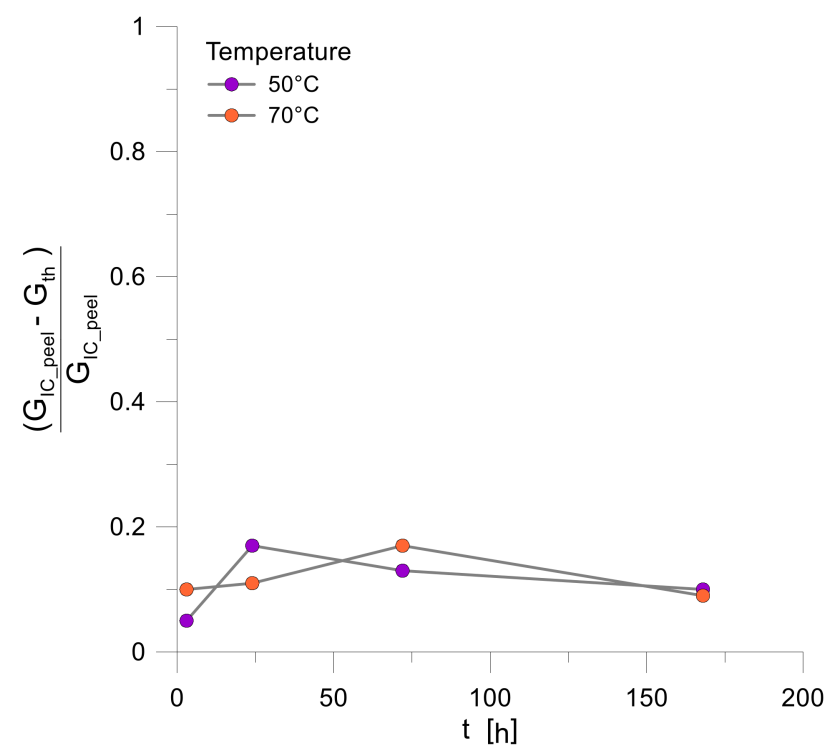

(b)

Figure 1. Percentage difference of fracture energy by IC-Peel software or current approach, as a function of (a) $v$ or (b) ageing time.

\section{Experimental Investigation}

A commercial multi-layer film for safety glass applications was investigated in the present study. According to Figure 2, the examined commercial tape was composed by two different layers made of PET, with a thickness of $0.11 \mathrm{~mm}$ (Layer 2) and $0.22 \mathrm{~mm}$ (Layer 1), and a PSA adhesive that was protected by environmental conditions by means of a removable release liner. 


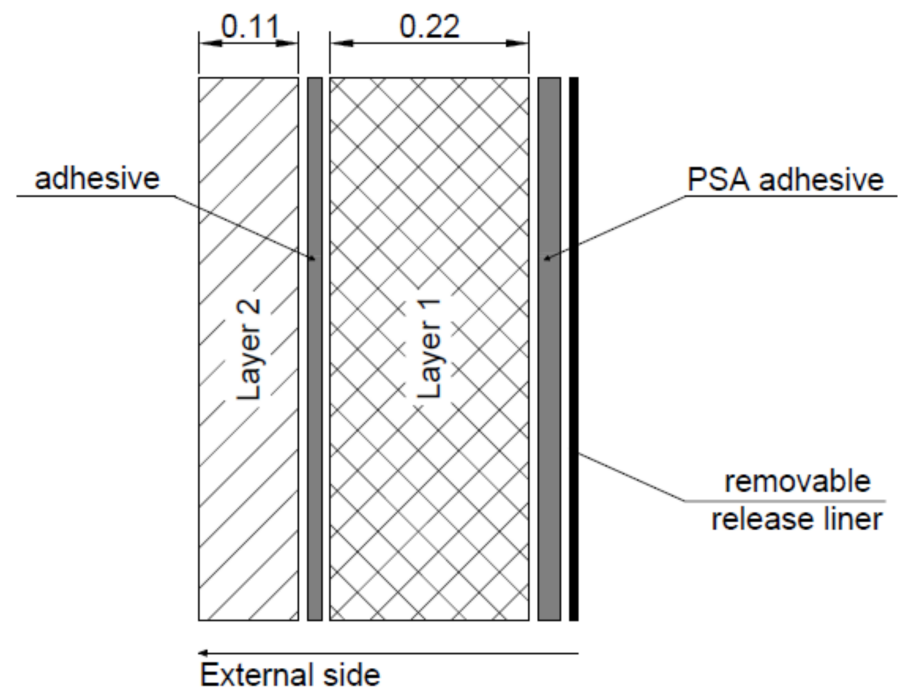

Figure 2. Stratification detail for the examined multi-layer ASF (values in $\mathrm{mm}$ ).

The first tests carried out included a tensile protocol, after treating the ends of the samples with glue (i.e., RS PRO Industrial Grade Adhesive 132633) in order to increase roughness and reduce slip to the grips. The tensile tests were conducted on five PET-film specimens, $350 \mathrm{~mm}$ in length (Figure 3a), according to ASTM D882-02 [27], which is adopted for plastics in the form of thin sheeting, including film with a thickness less than $1 \mathrm{~mm}$. Each layer of the film samples was also analysed with Differential Scanning Calorimetry and Fourier Transform Infrared spectroscopy. Moreover, the delamination behaviour of the tape from a $100 \times 40 \times 6 \mathrm{~mm}^{3}$ glass substrate was characterized by means of peel tests on rectangular specimens $25 \mathrm{~mm}$ in width (as shown in Figure $3 \mathrm{~b}$ and summarized in Table 1) by taking into account testing and ageing influence. These tests involved a limited number of specimens, with identical geometric characteristics, but treated differently in the pre-test phases. Some specimens were in fact aged in a dry-heat chamber, ventilated with constant temperatures, and for different periods of exposure, from 3 to $168 \mathrm{~h}$.

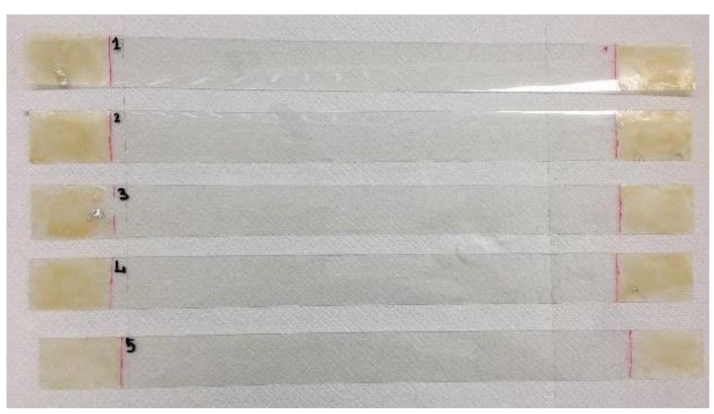

(a)

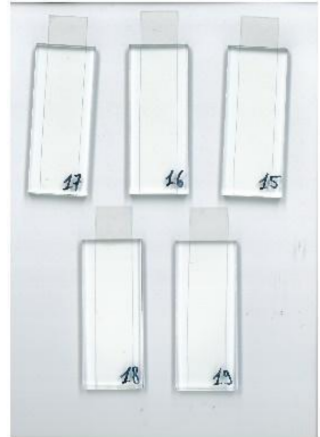

Figure 3. Example of (a) PET-film specimens for tensile tests and (b) selection of ASF-bonded glass samples for peel tests.

In this regard, it is important to clarify that the experimental setup of the peel test did not completely follow standard regulations. However, the sample preparation was considered necessary to minimize the influence of impurities or inclusions on the adhesion behaviour. The detailed dry lamination was carried out as in [28]. Both peel tests and tensile tests were performed using a Schimadsu Autograph AFS-X universal testing machine at a crosshead speed of $25.4 \mathrm{~mm} / \mathrm{min}$. 
Table 1. Summary of tested specimens (52 in total), listed as a function of temperature, ageing time and peeling rate.

\begin{tabular}{cccc}
\hline Specimen \# & $\begin{array}{c}\text { T } \\
{\left[{ }^{\circ} \mathbf{C}\right]}\end{array}$ & $\begin{array}{c}\text { Ageing Time } \\
{[\mathbf{h}]}\end{array}$ & $\begin{array}{c}\text { Displacement Rate } \\
{[\mathbf{m m} / \mathbf{m i n}]}\end{array}$ \\
\hline $1-4$ & 23 & - & 25.4 \\
1_2-4_2 & 23 & - & 50.8 \\
$1 \_3-4 \_3$ & 23 & - & 71.6 \\
$5-9$ & 50 & 3 & 25.4 \\
$10-14$ & 50 & 24 & 25.4 \\
$15-19$ & 50 & 72 & 25.4 \\
$20-24$ & 50 & 168 & 25.4 \\
$25-29$ & 70 & 3 & 25.4 \\
$30-34$ & 70 & 24 & 25.4 \\
$35-39$ & 70 & 72 & 25.4 \\
$40-44$ & 70 & 168 & 25.4 \\
\hline
\end{tabular}

\section{Numerical Analysis}

In support of the experimental methods, an FE numerical analysis was carried out in accordance with [28]. A 3-dimensional model was built in Abaqus/CAE [29] according to the layout and dimensions of the tape (total thickness of $36 \mu \mathrm{m}$ ) and the substrate, as described in Figure 2 and shown in Figure 4. Quasi-static analyses were carried out with the support of the Explicit solver.

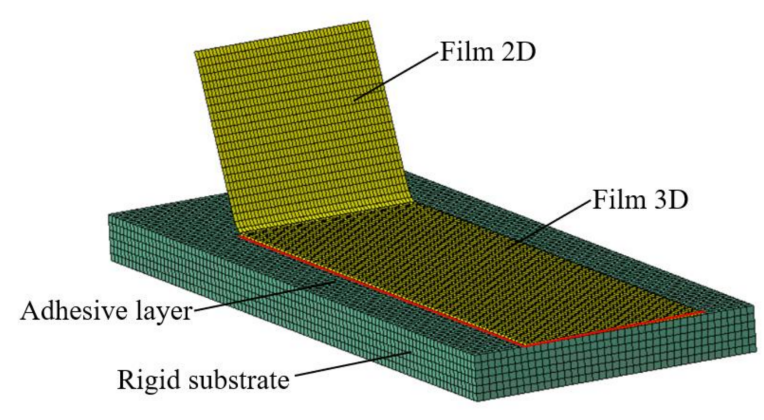

(a)

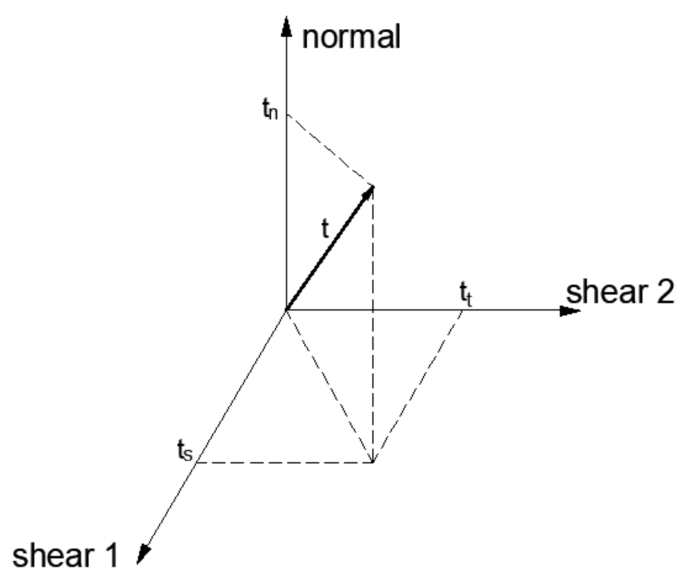

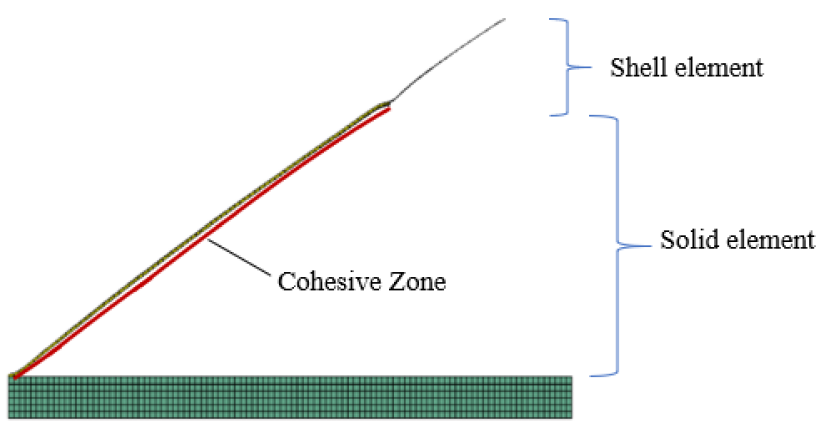

(b)

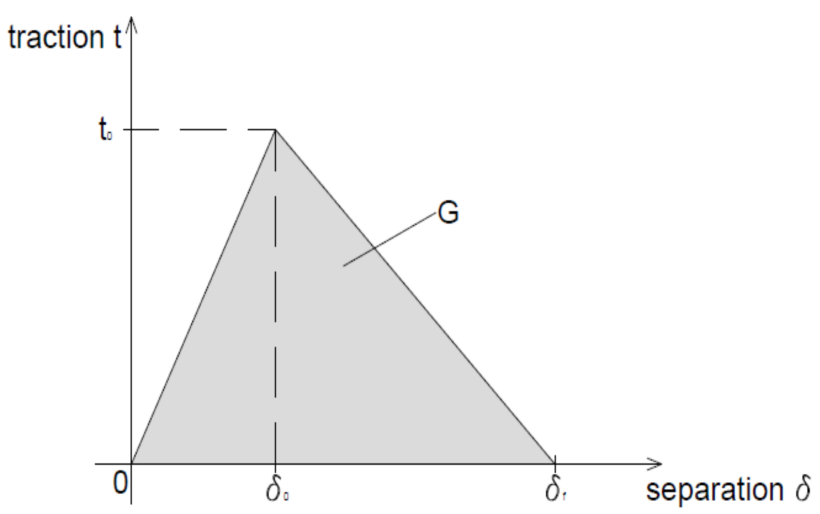

(c)

Figure 4. FE numerical model (Abaqus/Explicit): (a) assembly, (b) lateral view and (c) tractionseparation law in case of linear softening for damage evolution. 
The geometric model assembly (i.e., Figure 4a,b) consisted of C3D8R solid elements for glass substrates and the portion of film was expected to suffer from delamination, whereas the short vertical peel arm was represented in the form of S4R shell elements, to reduce the computational effort of the parametric peeling simulations.

As boundary conditions, the continuity restraint in the PET-film element was numerically described with a shell-to-solid connection. Furthermore, the lower surface of the glass substrate was clamped to reproduce the experimental setup.

The involved materials (glass, adhesive and PET) were modelled based on three different procedures. Glass was assumed to be linear elastic, with nominal mechanical parameters of annealed glass $\left(E_{g}=70 \mathrm{GPa}, v=0.23\right.$, i.e., hypothesis of rigid substrate). For the description of PET behaviour, an elastic-plastic material constitutive law was taken into account and calibrated based on tensile tests outcomes $\left(E_{P E T}=3.3 \mathrm{GPa}, \varepsilon_{y_{-} P E T}=2.7 \%\right.$ and $\nu=0.49$ ), with the addition of subsequent considerations of the accelerated ageing effects. Finally, for modelling the adhesive layer with very thin thickness, a surface-based Cohesive Zone Modelling (CZM)-based behaviour technique was employed. Therefore, PSA was modelled as a surface-to-surface interaction between the two bonded surfaces, by using a traction-separation law (Figure 4c), which consisted of three parts: a linear elastic behaviour, up to traction strength $\left(t_{0}\right)$ representative of damage initiation, and its evolution down to separation failure $\left(\delta_{t}\right)$. The elastic term is commonly defined by a constitutive matrix $K$, as a function of film elastic moduli $E_{a d h}$ and $G_{a d h}$, that relate the nominal stresses to the separation across the crack tip [29]:

$$
t=K \delta \rightarrow\left\{\begin{array}{c}
t_{n} \\
t_{s} \\
t_{t}
\end{array}\right\}=\left[\begin{array}{ccc}
K_{n n} & 0 & 0 \\
0 & K_{s s} & 0 \\
0 & 0 & K_{t t}
\end{array}\right]\left\{\begin{array}{c}
\delta_{n} \\
\delta_{s} \\
\delta_{t}
\end{array}\right\}
$$

where $t$ and $\delta$ represent stress and separation vectors, respectively. The former consists of three components: a normal traction $t_{n}$ and two shear tractions, $t_{s}$ and $t_{t}$. The corresponding separations, i.e., the relative displacements between the top and bottom surfaces of the cohesive layer, are denoted by $\delta_{n}, \delta_{s}, \delta_{t}$, respectively. Moreover, $K_{n n}=E_{a d h} / t_{a d h} ; K_{s s}=K_{t t}=$ $G_{a d h} / t_{a d h}$.

The off-diagonal terms in the stiffness matrix are zero due to uncoupled elastic behaviour assumption. Further elements are required to complete the CZM definition. Firstly, several damage initiation criteria are available in the Abaqus library, such as the maximum principal stress criterion (MAXPS), the maximum principal strain criterion (MAXPE), the maximum nominal stress criterion (MAXS), the maximum nominal strain criterion (MAXE), the quadratic nominal stress criterion (QUADS), and the quadratic nominal strain criterion (QUADE).

The first two criteria (MAXPE and MAXPS) refer to the main direction, and therefore the crack always develops in the orthogonal direction of deformation and stress to the main one, respectively. In the other criteria, instead, the user can choose the direction of crack. The maximum nominal stress (MAXS) criterion was used in the present analyses, based on the limit condition [29]:

$$
\left\{\frac{t_{n}}{t_{n}^{0}} ; \frac{t_{s}}{t_{s}^{0}} ; \frac{t_{t}}{t_{t}^{0}}\right\}=1
$$

where $t^{0}{ }_{n}, t^{0}{ }_{s}, t^{0}{ }_{t}$ denote the peak stresses related to pure failures ( $n=$ normal direction; $t$ and $s=$ first or second shear directions) at the interface. These input parameters were computed from experimental peeling tests outputs, together with the fracture energy value $G$, which was iterated to find a good match between experimental and numerical peel curves (starting from provisional values derived by the proposed theoretical approach).

Furthermore, it has to be noted that the damage evolution criterion is a function of fracture energy $(G)$. To follow the advancing crack tip, a scalar damage variable $(D)$ was hence provided during the numerical simulations (CSDMG parameter). It starts at a value of 0 at the initiation of damage, and then the $D$-value monotonically increases until it 
reaches 1 , so as to represent a fully damaged material and a complete loss of cohesive bond. This follows the degradation of material stiffness given by [29]:

$$
t=(1-D) \bar{t}
$$

where $\bar{t}$ represents the stress predicted by the linear elastic traction-separation law.

In this study, an energy-based method was used. In particular, a Mode-Independent behaviour was considered in which the fracture energy $G$ was set to correspond to the first mode energy, and to represent the work carried out by normal stress.

Following the above considerations, the detailed calibration of the reference FE model for peel test simulations was based on the experimental results from delamination tests, herein discussed (Sections 5 and 6). This allowed the development of a consistent CZM law for the selected ASF product, and a realistic description of the stress state around the crack tip in different ageing conditions.

\section{Discussion of Experimental Results}

\subsection{Materials Investigations}

Differential Scanning Calorimetry (DSC) is a thermal analysis technique that evaluates the heat exchange difference between sample and reference as a function of temperature and time. The result obtained from this analysis is a thermogram in which the difference in thermal flow measured between sample and reference is reported as a function of temperature. In the case of crystalline or semi-crystalline materials, information on the melting and crystallization temperature and enthalpy associated with phase change is obtained.

In this paper, DSC thermograms of the PET-film samples were measured with a Netzsch DSC 200 F3 Maia in nitrogen atmosphere, from $25^{\circ} \mathrm{C}$ to $290^{\circ} \mathrm{C}$, at a heating rate of $10 \mathrm{~K} / \mathrm{min}$. The melting point and melting enthalpy were determined according to ISO 11537-3. Glass transition experience was determined according to ISO 11537-2.

Layer-1 (blue curve in Figure 5) and Layer-2 (red curve in Figure 5) thermograms show a primary melting point around $257^{\circ} \mathrm{C}$ (with melting enthalpy of $44-50 \mathrm{~J} / \mathrm{g}$ ); these values are consistent with the typical values found in the literature for semicrystalline PET [30]. Layer-2 also shows a secondary melting peak at $243{ }^{\circ} \mathrm{C}$ : the presence of a second polymer, blended with the PET, could be speculated. Polybutylene terephthalate (PBT) and Polytrimethylene terephthalate are often used in PET/PBT and PET/PTT blends [31] and their melting temperature is consistent with this secondary melting peak.

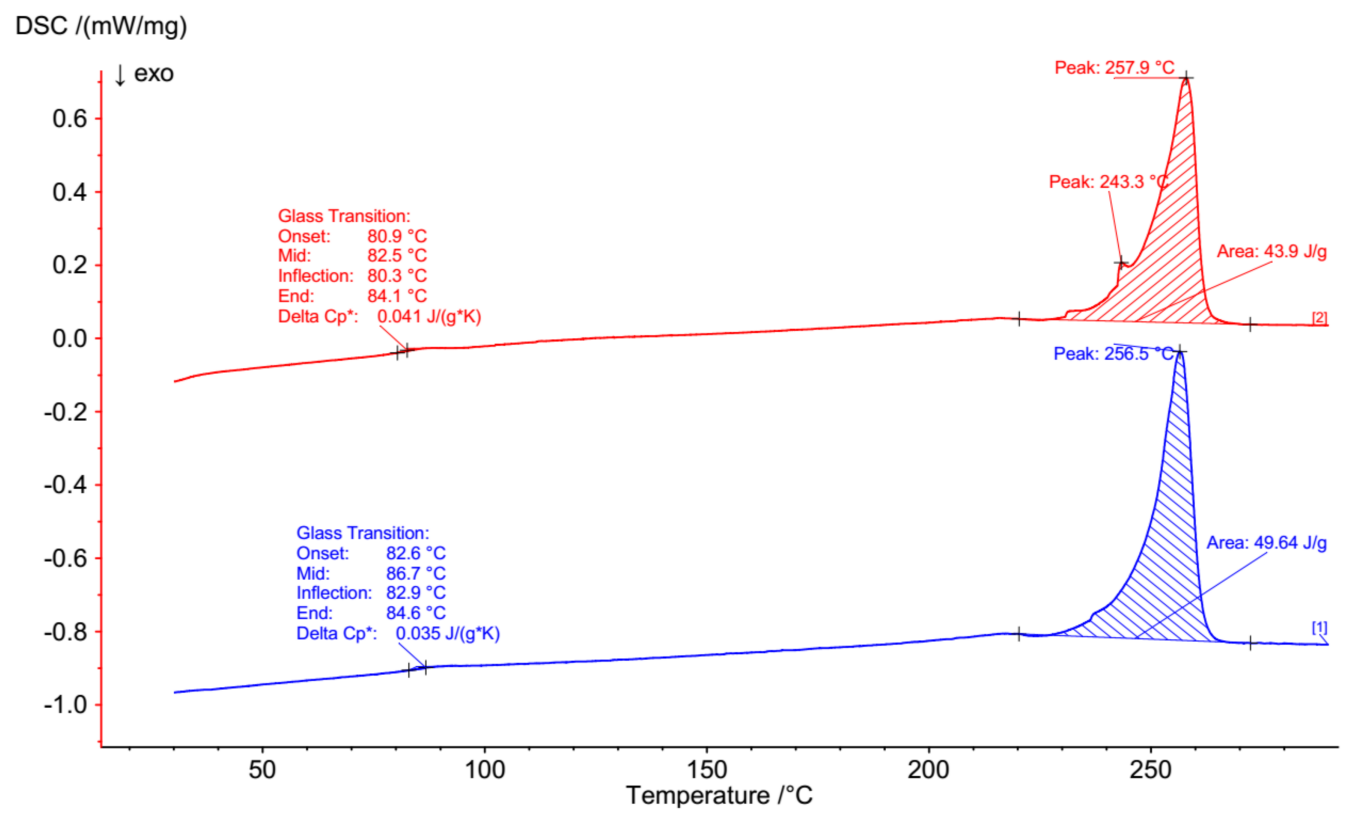

Figure 5. DSC heating thermograms of Layer-1 (blue) and Layer-2 (red). 
Fourier Transform Infrared spectroscopy (FT-IR) is a technique that allows investigation into the chemical nature of materials by analysing the vibrational bands associated with different functional groups. Spectra were acquired with a Thermo-Nicolet Nexus 470 spectrometer equipped with an Attenuated Total Reflectance (ATR) accessory, in the spectral range of $4000-400 \mathrm{~cm}^{-1}$.

FT-IR spectra of protective film, both sides of Layer-1 (Figure 6, red curves) and spectrum of the internal side of Layer-2 (Figure 6, blue curve) show vibrational bands consistent with those of PET [32]. FT-IR spectrum of the external side of Layer-2 (Figure 7) show different vibrational bands, which are consistent with an amine. This could be attributed to a surface treatment of the PET film. Such compounds are often used as stabilizers or UV absorbers [33]. FT-IR spectrum of the PSA adhesive (Figure 8) shows vibrational bands associated with $\mathrm{CH}_{3}, \mathrm{CH}_{2}, \mathrm{C}-\mathrm{O}-\mathrm{C}$ e $\mathrm{C}=\mathrm{O}$ groups and Amide-I vibration [34], consistent with those of a commercial adhesive labelled as "polyurethane adhesive".

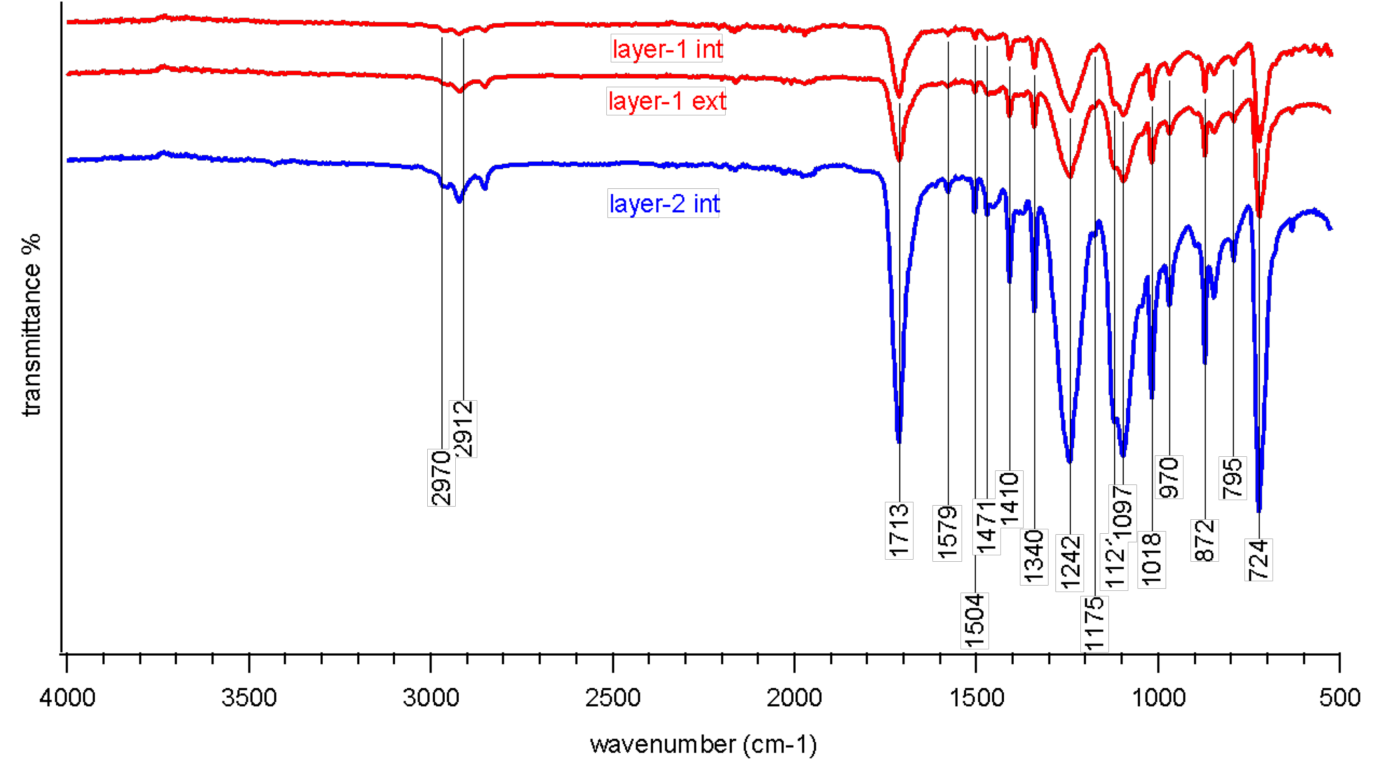

Figure 6. FT-IR spectra of Layer-1 (both sides, in red) and Layer-2 internal side (blue).

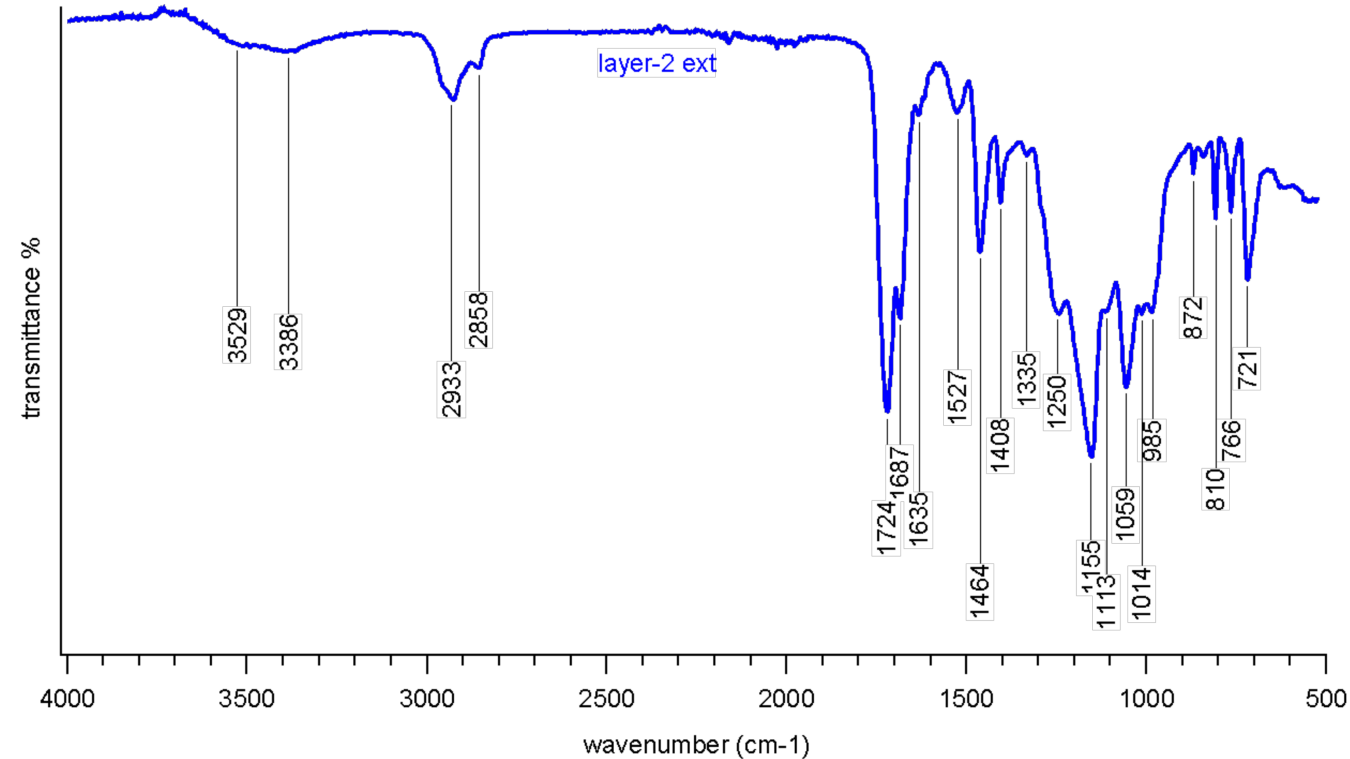

Figure 7. FT-IR spectra of Layer-2, external side. 


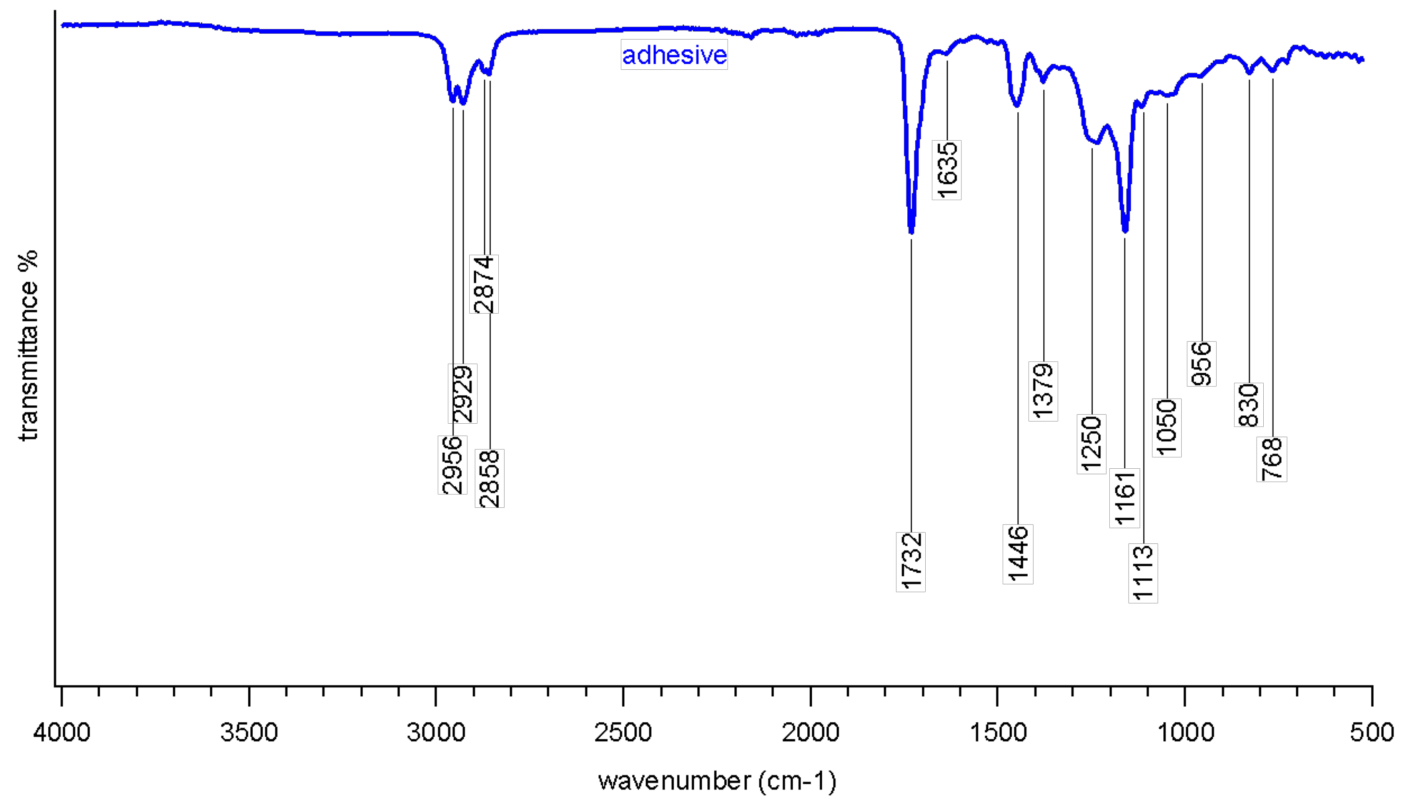

Figure 8. FT-IR spectra of adhesive layer.

\subsection{Mechanical Investigation}

\subsubsection{Tensile Test}

Firstly, the tensile investigation was carried out to provide a proper measure of basic mechanical parameters for PET, and especially to allow considering the tape extensibility in the portion no longer in contact with glass substrate, for delamination tests. It is in fact confirmed by several studies the degradation effect of ageing on PET mechanical parameters [35-40]. Starting from the slope of the tangent on the first linear portion of the stress-strain curve, the values for the elastic modulus $(E=3310 \mathrm{MPa})$, yield stress and yield strain were hence determined. The experimental setup initially described in Section 3 is shown in Figure 9, while the advancing phases of test are schematized in Figure 10.

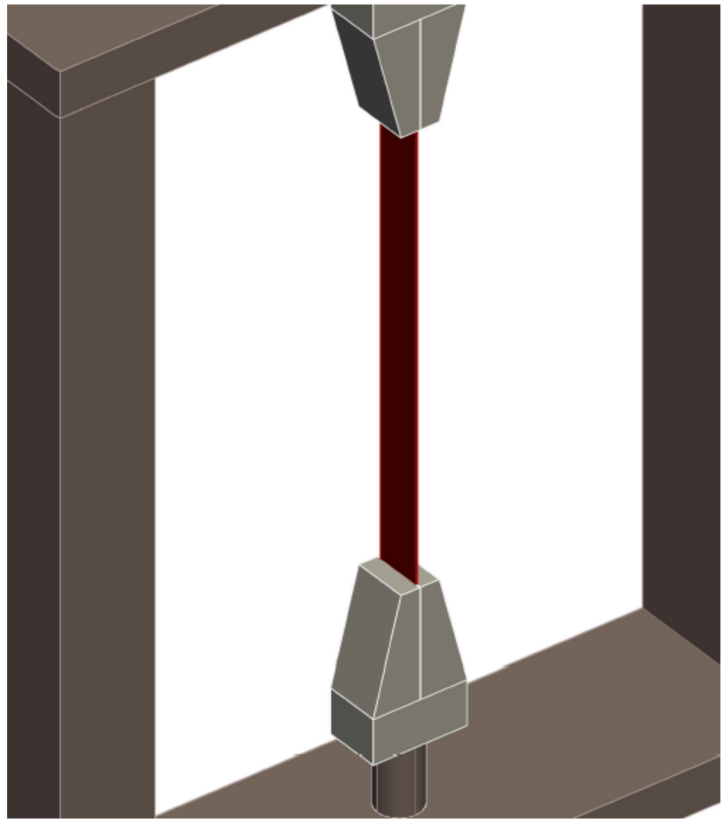

(a)

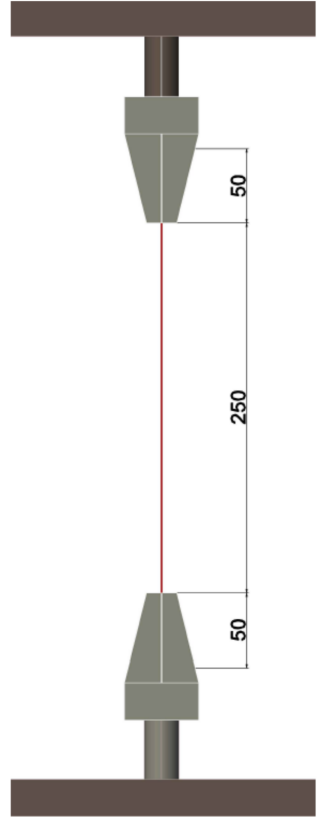

(b)

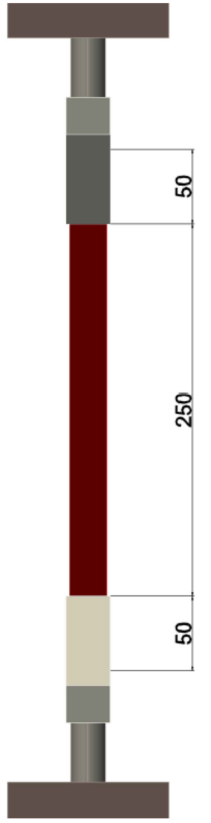

(c)

Figure 9. Tensile test setup (values in mm). (a) 3D view, (b) frontal view, (c) lateral view. 


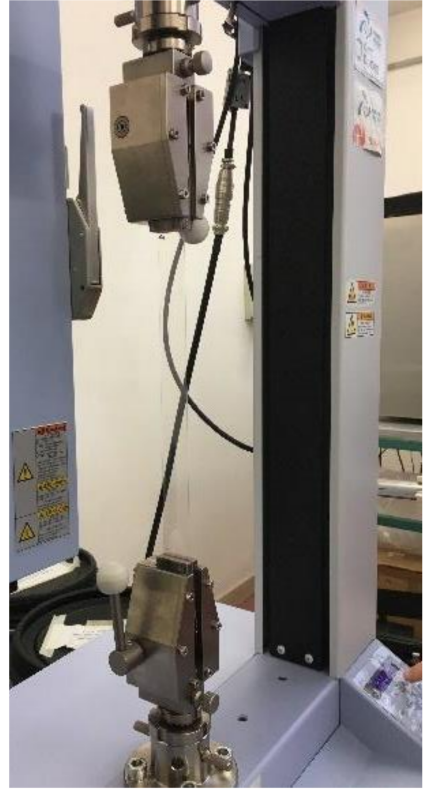

(a)

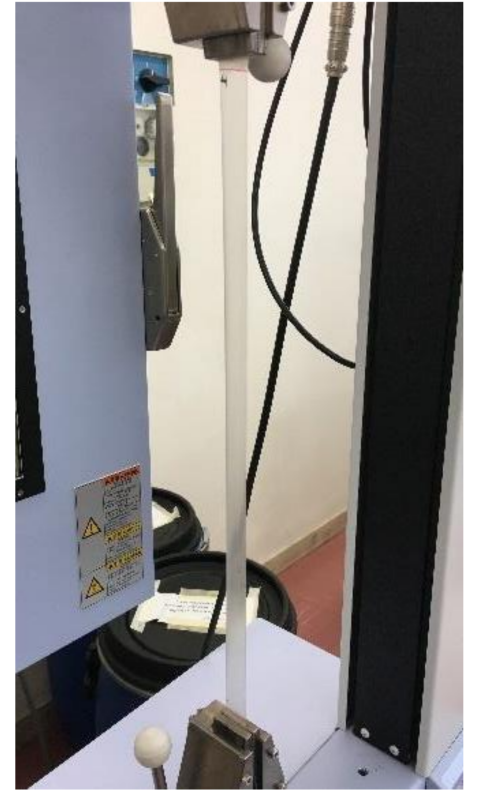

(b)

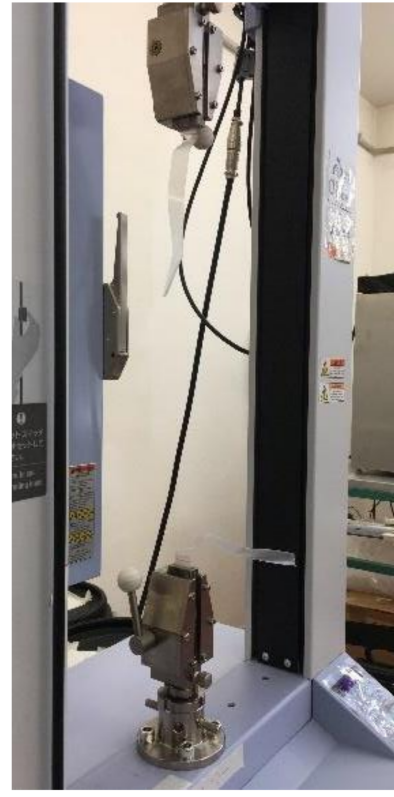

(c)

Figure 10. Tensile test at (a) initial step, (b) yielding step and (c) failure step.

The yielding stage of PET corresponds to an opacification of the amorphous layer indicating permanent deformation, and the failure is achieved when about $80 \%$ of elongation at break is reached (see also Figure 11).

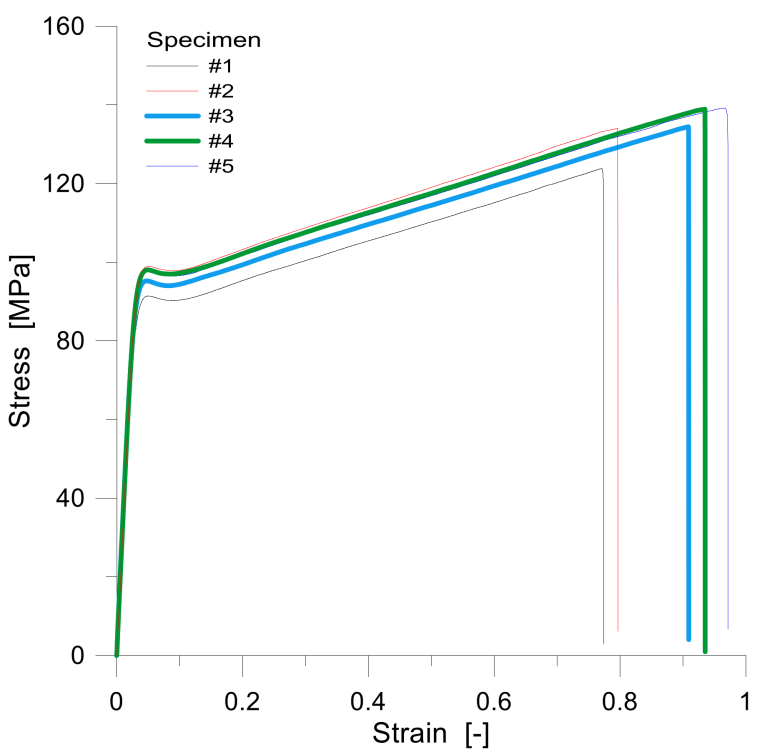

(a)

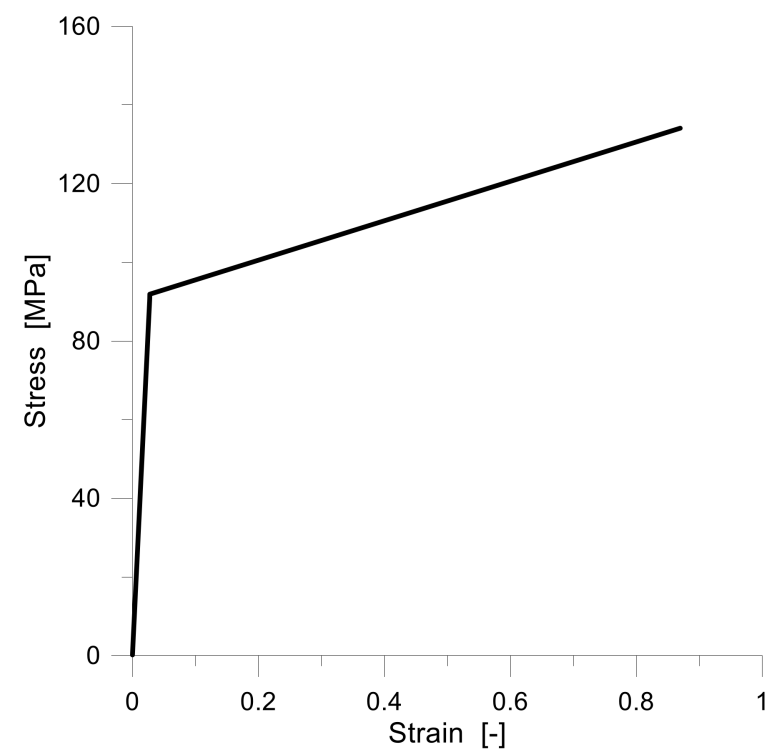

(b)

Figure 11. Tensile test output: (a) experimental stress-strain curves and (b) mechanical behaviour model.

In the post-processing stage of tensile test results, elastic and plastic regions were fitted separately with straight lines. To be more accurate, the stress-strain curve may be generalized in the form of a bilinear curve. After a stress peak in the first portion, the curve follows a descending branch and then starts to grow again with constant slope until breaking (Figure 11). 


\subsubsection{Peel Test}

There are several international standard methods for peeling tests, such as those published by the American Society for Testing of Materials (ASTM) or by the International Organization of Standardization (ISO) [41-43]. The results of these tests are substantially different for the way the load is applied to the sample. However, there are many similarities in their basic principles. All methods describe, in fact, the use of rectangular samples with constant adhesion thickness $(t)$ and large width to thickness $(b / t)$ ratios. In a peeling test, it is customary to specify the geometry parameters of the strip that is going to delaminate, generally called "peel arm".

The sheets of starting film, with which the interfaces have been realized for the present study, were characterized by a total size of about $1.05 \times 1.2 \mathrm{~m}^{2}$, from which samples in the form of strips with dimensions $25 \times 120 \mathrm{~mm}^{2}$ were obtained. The peeling was conducted in a standard testing machine, where the force was measured by means of a load cell. Unlike standard requirements, the test configuration schematized in Figures 12 and 13 did not keep the peel angle at $\theta$ constant but was characterized by $\theta$ values decreasing from $90^{\circ}$ immediately before the complete separation of films. This stage corresponded to the end of each test, as also in accordance with [44].

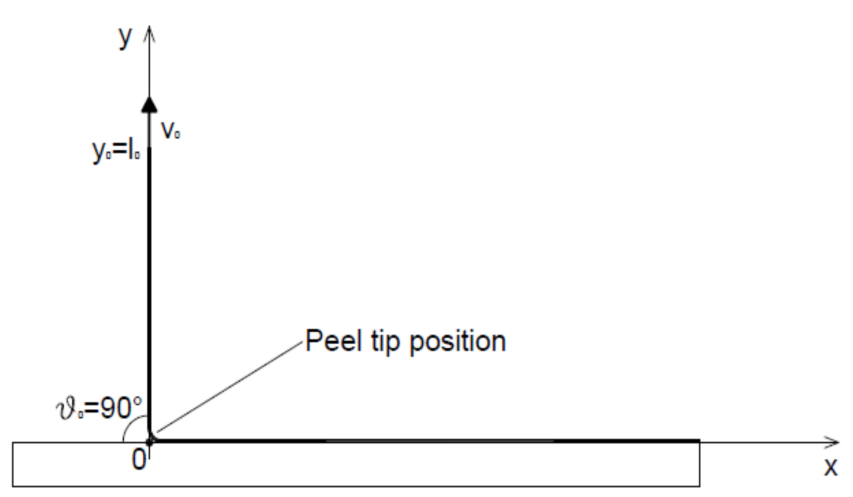

(a)

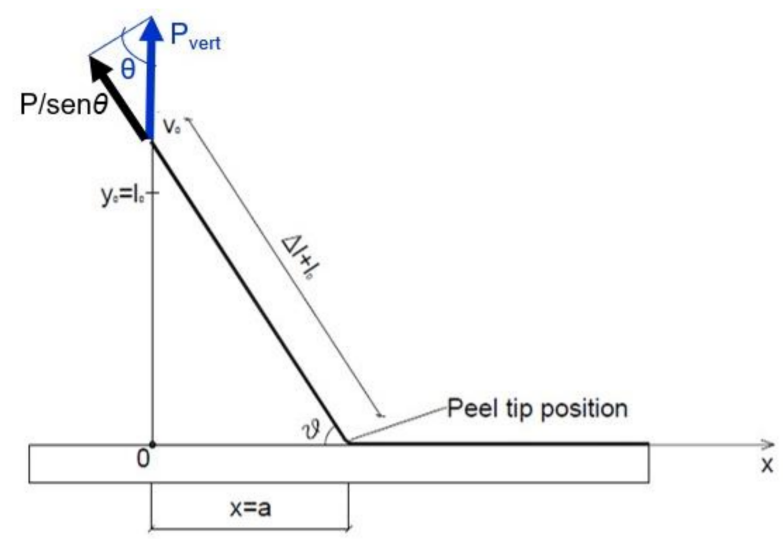

(b)

Figure 12. Configuration of peeling process at $(\mathbf{a}) t=0$ and $(\mathbf{b}) t=i$.

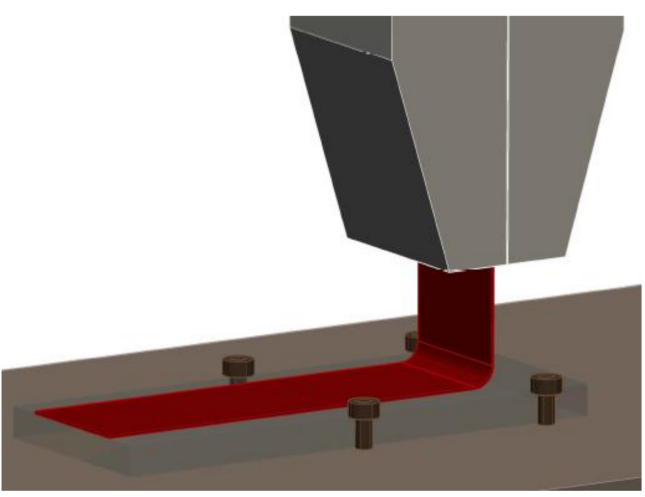

(a)

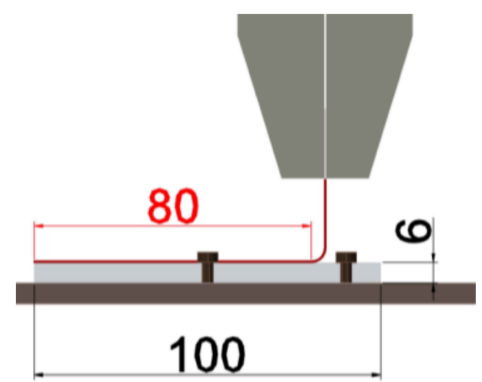

(b)

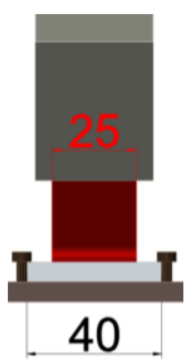

(c)

Figure 13. Experimental setup of peel test (values in mm). (a) 3D view, (b) frontal view, (c) lateral view.

In further detail, the specimens were installed on the machine through 4 bolts, 2 per side, in order to guarantee a fixed connection and avoid the displacement of the support during the test. The film, previously glued to the support, was then folded and stuck in the machine clamp. No external equipment was used to measure displacements, and the 
diagrams deriving from laboratory tests were measured from machine data only. In order to calculate adhesion energy according to Section 2 and the effective peel force along the peel arm direction, the measurement of angle values required careful consideration, as in the following.

Figure 12 shows, in fact, the evolution of the delamination process. Based on some geometrical considerations, the peel angle $\theta$ for each instant of time $i$ can be generally evaluated in Figure 12 as:

$$
\left(l_{0}+\Delta l\right)^{2}=y^{2}+a^{2}
$$

where $l_{0}$ is the initial peel arm length, $y$ is the vertical imposed displacement, $a$ is the advancing peel tip position and $\Delta l$ (as function of $\theta_{i}$ ) represents the elongation of the peel arm length by elastic and plastic deformation of the tape due to the application of the peeling load.

The result of the test is the peel force, which does not exactly represent the true toughness of the adhesive interface, but a combination of the toughness of the interface, thanks to the adhesive and the work spent to deform the peel arm elastically and plastically if the substrate is infinitely rigid, as in the present investigation. Figure 14a shows the typical experimental plots of (a) peel force vs. imposed displacement by the test machine and (b) the same plots with the component along the peel arm direction on the $y$-axis.

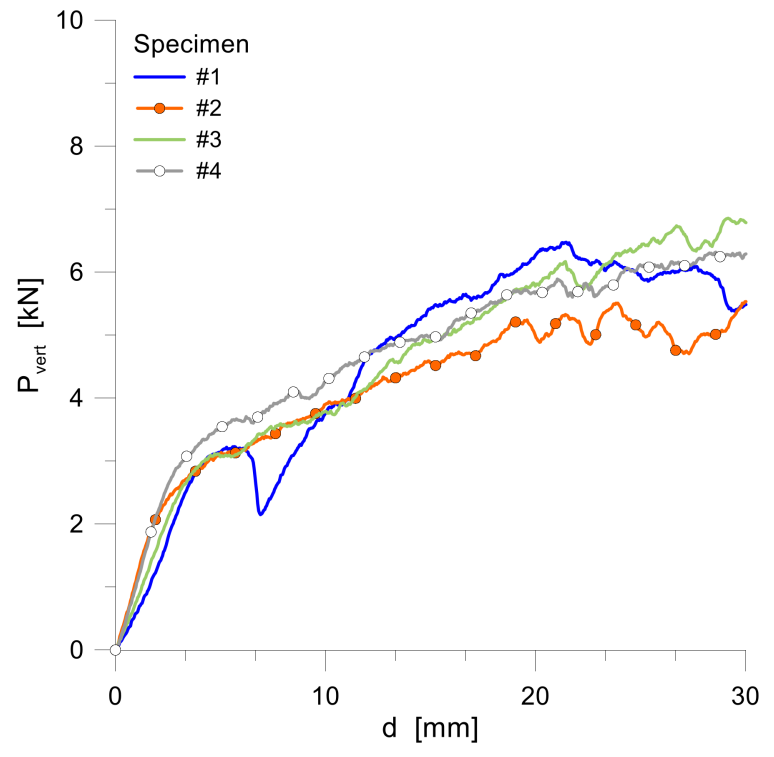

(a)

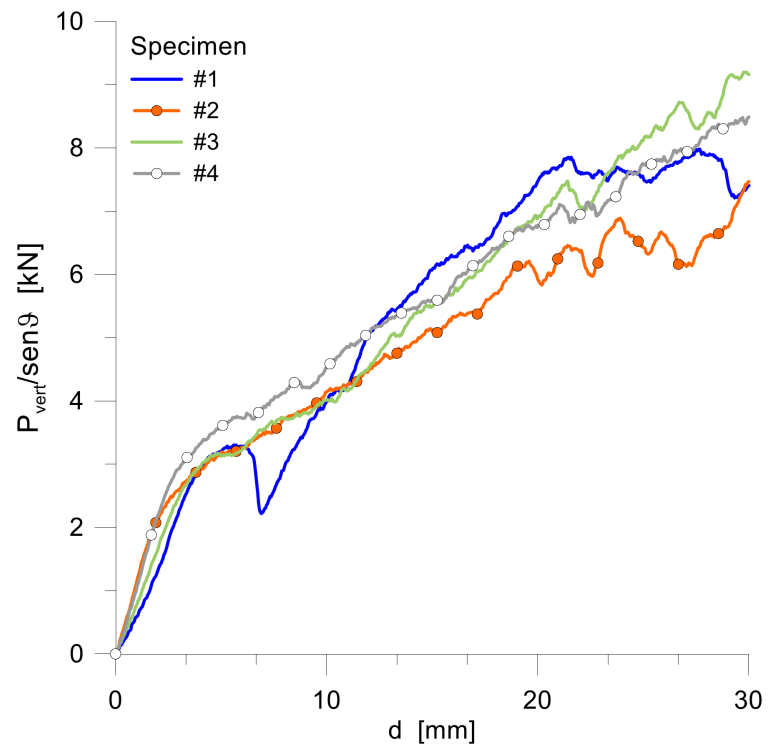

(b)

Figure 14. Peel curves of unaged samples (specimens 1-4) in terms of (a) $P_{\text {vert }}$ and (b) its component along peel arm direction.

As the adhesive is peeled, it is possible to see that the force increases until it levels off at a roughly steady-state value. This is the steady-state region, where the focus of this study is directed. The peel force $P$, obtained as the vertical load computed from the load cell data divided by $\sin \theta$, is taken as an average of values in this region (in general, past $25 \mathrm{~mm}$ ). Nevertheless, this aspect is less recognizable than in the case of a constant-angle peel test, where equilibrium is reached due to the continuously varying tip velocity as a function of angle, while the applied extremity velocity remains constant.

\subsubsection{Effect of Peel-Rate and Ageing}

Peel-rate effect was studied by conducting peel tests over a range of three rates for a constant thickness $t$ of $36 \mu \mathrm{m}$ on twelve specimens, as reported in Section 3. Generally, the rate dependence of results in a physical phenomenon can be important in many engineering, biology and chemistry applications. Due to the viscoelastic behaviour of PET material, 
the peeling rate should show a significant effect on the peeling test, and therefore on the adhesive response. Alfano and Musto proposed in [45,46] a cohesive zone model (CZM) for a viscoelastic material and a rate-dependence law based on the evolution of a damage parameter $D$ by combining two dissipation mechanisms: elastic decohesion and viscous delamination.

As shown in Figure 15a-c, the shapes of the experimental curves are quite similar. Moreover, it can be noted that the peeling force increases, initially, up to the onset of interface propagation. Comparing the peel-off force in the steady-state process, it is reasonable that the peel force-peel rate relation has a positive slope (i.e., Figure 15d), such as the elongation at break.

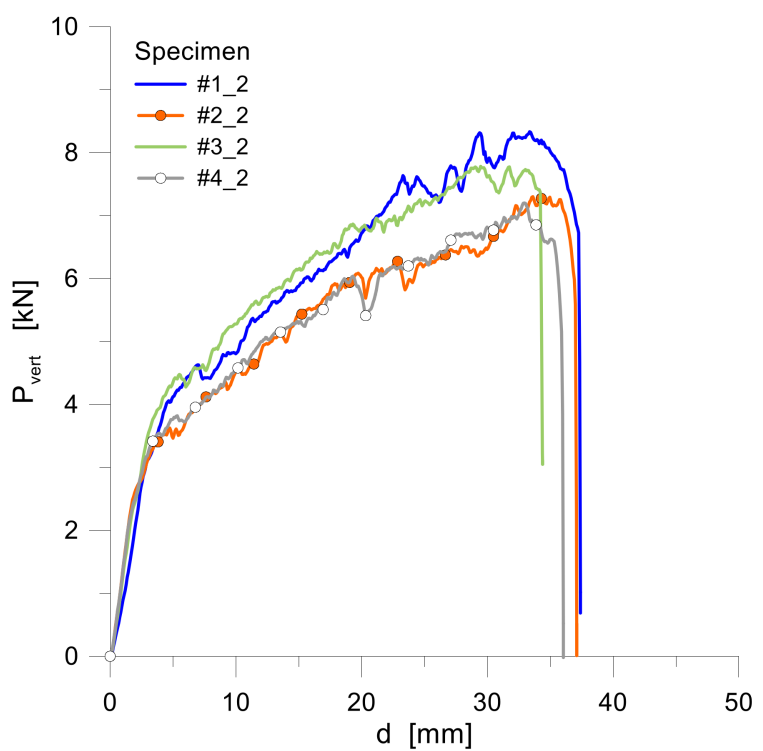

(a)

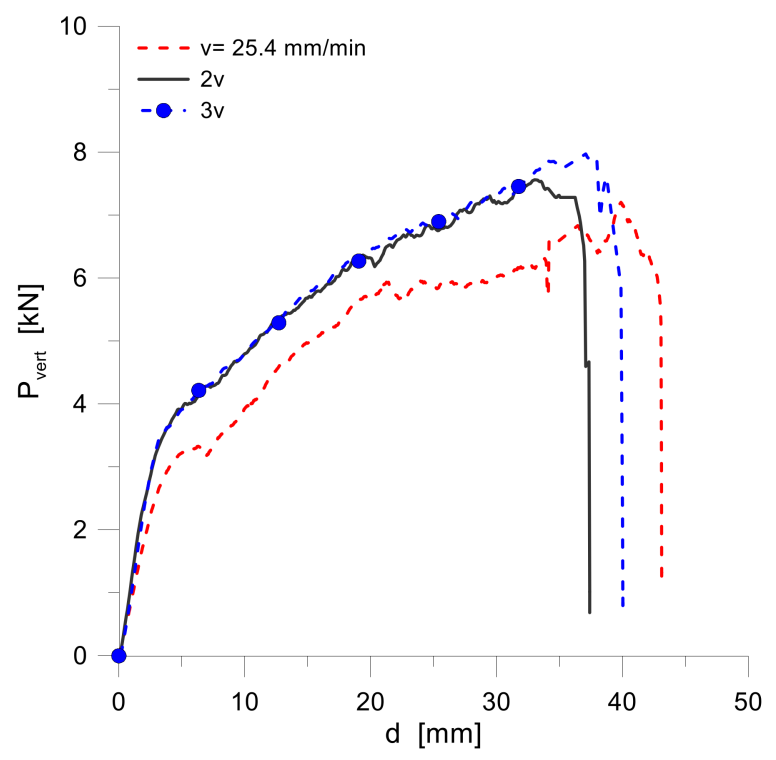

(c)

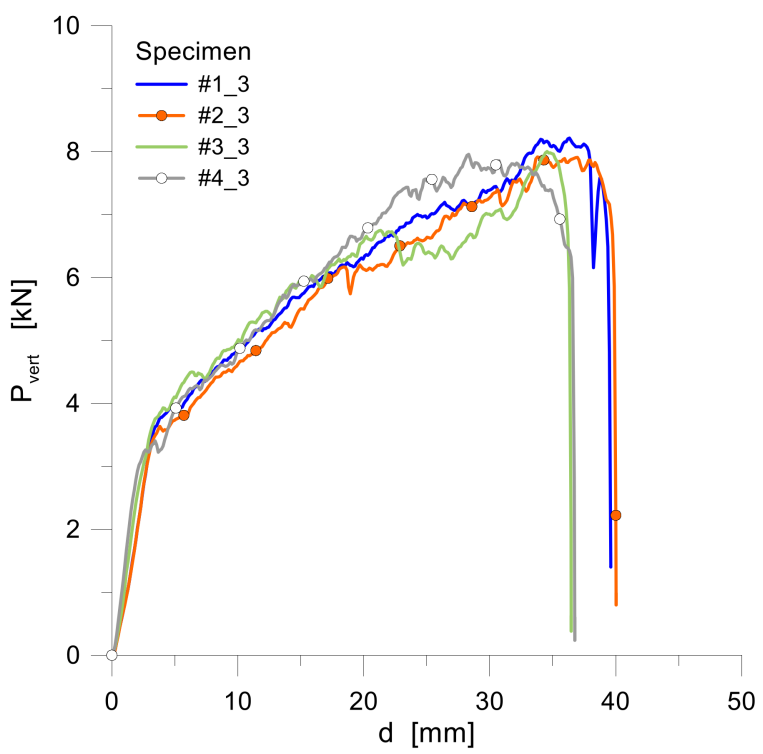

(b)

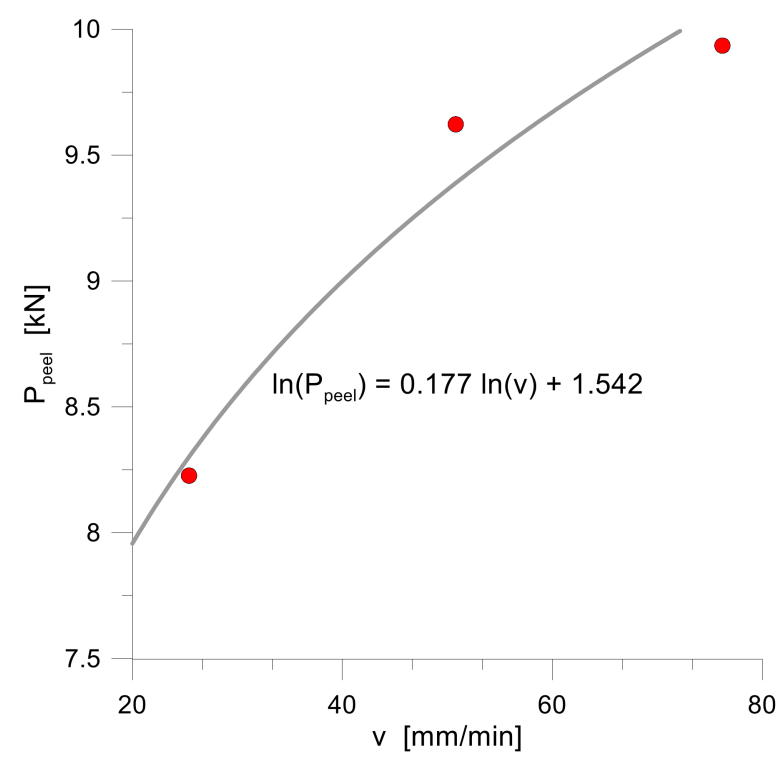

(d)

Figure 15. Experimental results with respect to (a) 2v, (b) 3v; (c) a comparison of mean curves with respect to peel rate and (d) peel force-peel rate correlation.

Therefore, to assess the ageing dependent peel behaviour, and in particular the performance of tapes used for ASF, the specimens were heated to two different temperatures, 
$50{ }^{\circ} \mathrm{C}$ and $70{ }^{\circ} \mathrm{C}$, for four different times of exposure, namely $3 \mathrm{~h}, 24 \mathrm{~h}, 72 \mathrm{~h}$ and 1 week, according to BS EN ISO 9142:2003 [47] and Table A.1 for temperature, Section A.3 for duration of exposure and Section A.4 for relative humidity. This characterization was necessary in order to simulate the more or less unfavourable environmental conditions to which the examined films can be exposed in operational conditions. The specimens were all tested at room temperature, generally after $10 \mathrm{~min}$ of artificial ageing.

Compared to unaged samples $\left(P_{\text {peel_av }}=8.27 \mathrm{kN}\right)$, the experimental results in Figure 16 show that the peeling force after $3 \mathrm{~h}$ of heating treatment (at all test temperatures) gives evidence of a significant upward trend. Moreover, between the two temperatures, the peel strength does not increase largely. The maximum values, for $50{ }^{\circ} \mathrm{C}$ and $70{ }^{\circ} \mathrm{C}$, are observed at the highest period of exposure and at $24 \mathrm{~h}$, respectively. This depends on the sensitivity of the tape near the glass transition temperature, where the material loses stiffness and therefore the force required for detachment decreases.

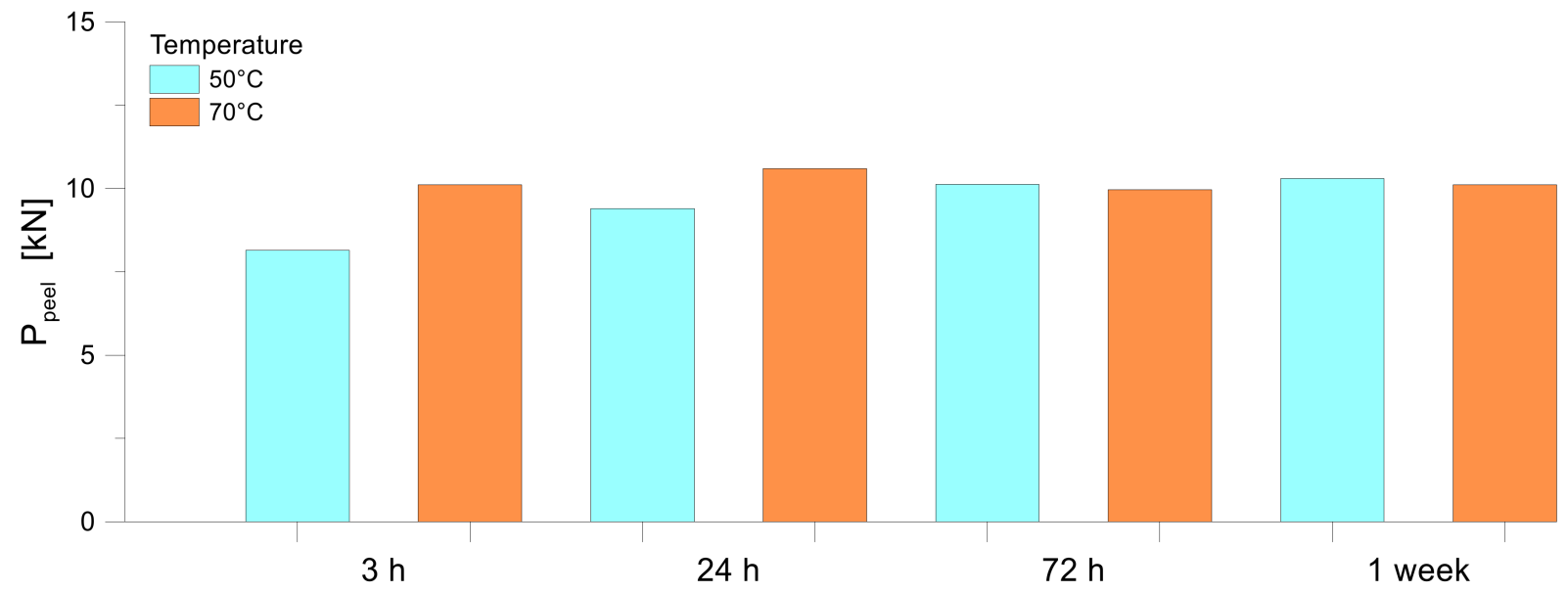

Figure 16. Peel force-ageing time for each imposed ageing temperature.

\section{Coupled Experimental and Numerical Analysis}

\subsection{Peel Rate}

In the diagrams shown in Figure 17, the analytical curves derived by the iterative processes, in which the only variable is the fracture energy input, are compared to the experimental ones. It is worth noting the general good correlation of FE numerical curves, estimated by the reference FE model as in Section 4, and the corresponding experimental data.

Besides, the same comparative data can be used for a discussion of fracture energy for the tested samples. In this regard, Figure 18 shows a clear dependency of the fracture energy on the peel rate, as obtained for grouped tests that were conducted at several peel velocities (Table 1$)$. As far as the peeling rate increases $\left(v_{2}=2 v\right.$ and $v_{3}=3 v$, respectively), the corresponding fracture energy calculated based on Section 2 slightly increases (i.e., Figure 18a). Different evidence was derived from FE numerical simulations of the same specimens, by which the value of $G$ was found to remain mostly constant for $v_{2}$ and $v_{3}$ (Figure $18 \mathrm{~b})$. The variability was measured in the order of $20 \%$ when the rate doubled $\left(v_{2}\right)$, while for $v_{3}$ the influence on $G$ was found negligible. The observation that the value of $G$ increases as the peel velocity increases is a predictable outcome, which is also in agreement with several literature data.

The rate of extension in a peel test is given approximately by $v / t_{\text {film }}$, where $v$ is the peel rate and $t$ is the thickness of the tape. Generally, for low or high rates, the transition phenomenon changes as described in Section 2. Low rate typically means a transition from liquid-like to rubber-like behaviour, while high rate means a transition from rubber-like to glass-like behaviour. 


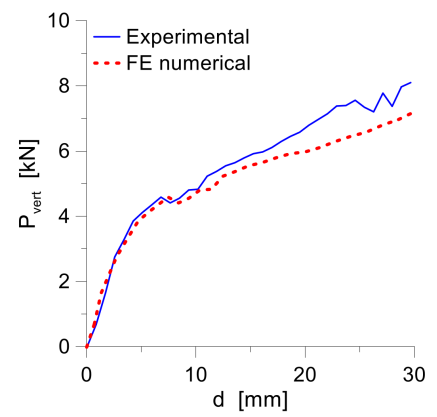

\#1_2

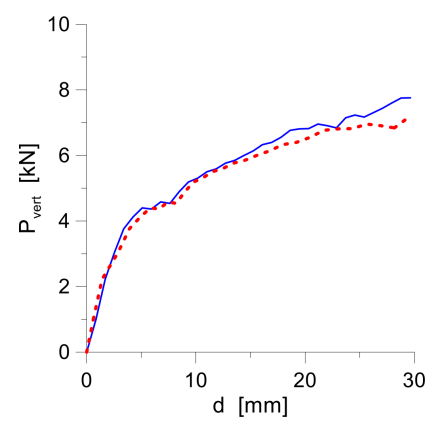

\#3_2

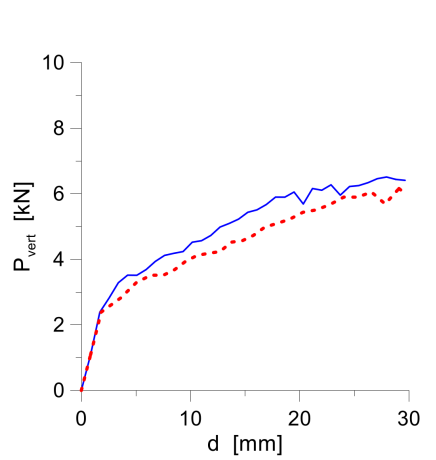

\#2_2

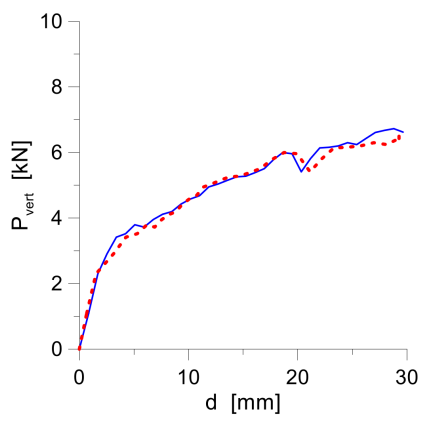

\#4_2

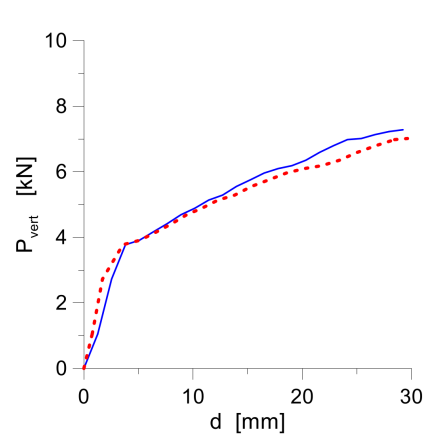

\#1_3

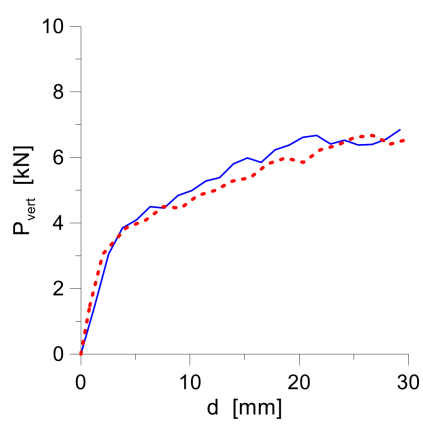

\#3_3

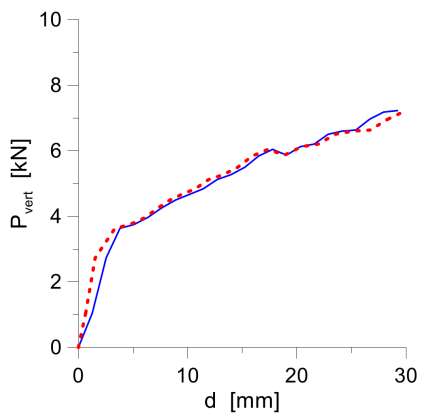

\#2_3

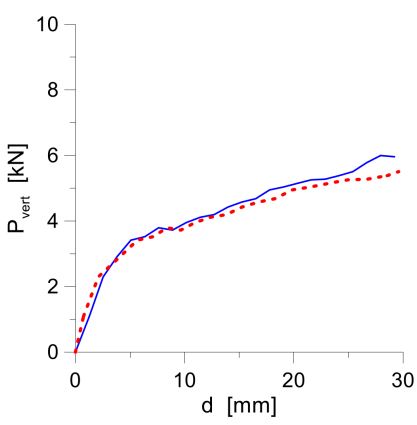

\#4_3

(a)

(b)

Figure 17. Comparison between FE numerical and experimental peel curves, as observed at peel rates equal to (a) $2 v$ or (b) $3 v$.

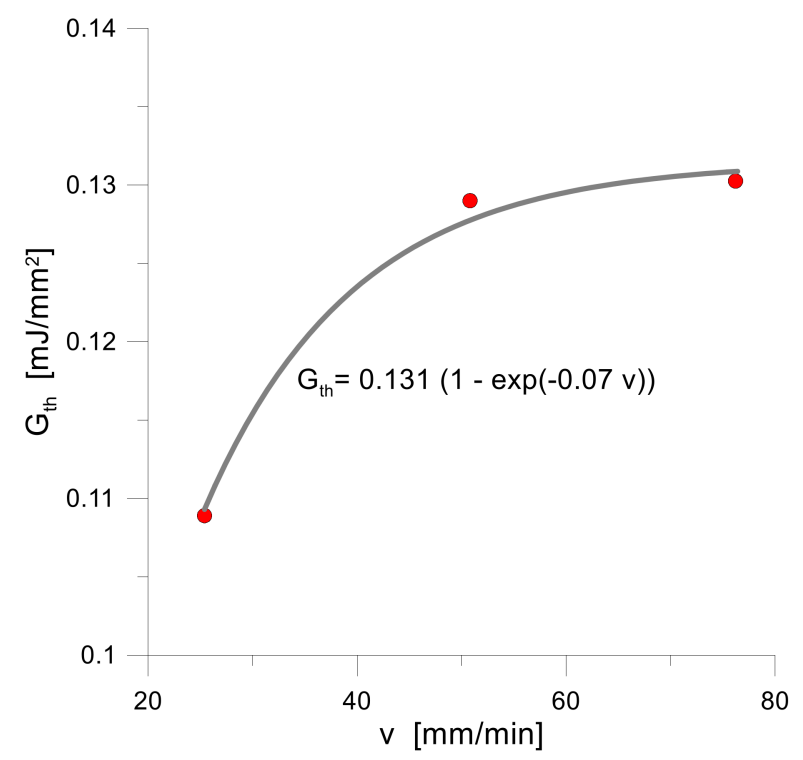

(a)

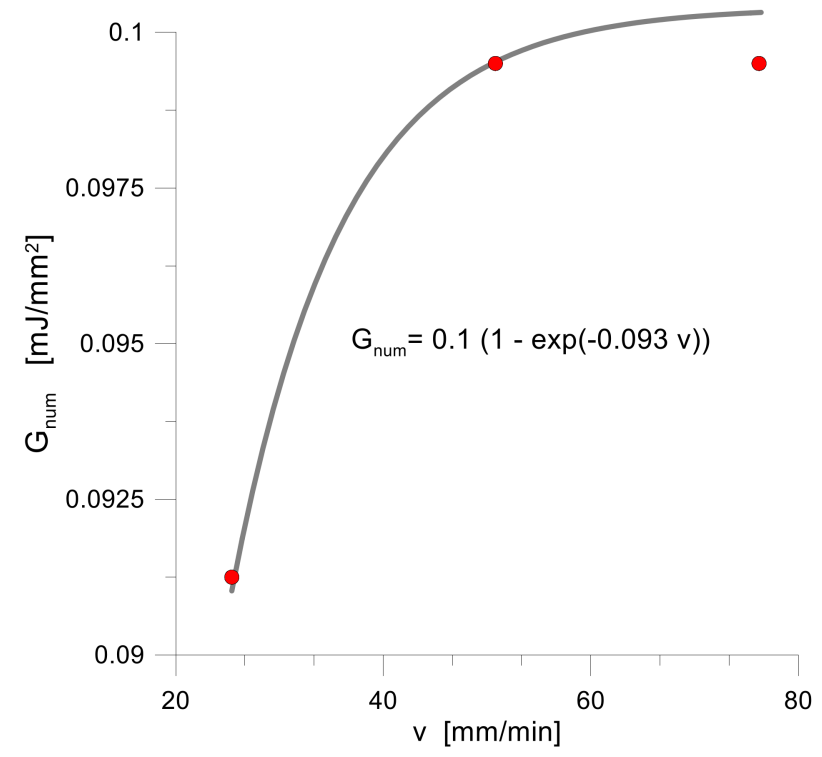

(b)

Figure 18. Fracture energy calculated (a) by modified Kinloch expressions or (b) by corresponding FE numerical simulations, as a function of peel rate.

Moreover, the cohesive failure mechanism can be turned into an interfacial failure if the peeling rate increases up to a critical value after which peel strength no longer follows a growth trend (i.e., Figure 19). In this case, the sudden change is due to higher rates at higher 
temperatures [21]. As the peeling rate continues to increase, the peel force also increases in this region and the peel is smooth and steady. At some point, the peel will oscillate when tested using a constant rate. This unstable region is often referred to as a "shocky" peel $[48,49]$. In general, when the failure mode changes from cohesive to interfacial as the temperature increases, the peel strength decreases. Conversely, as the peel rate is increased, peel strength increases.

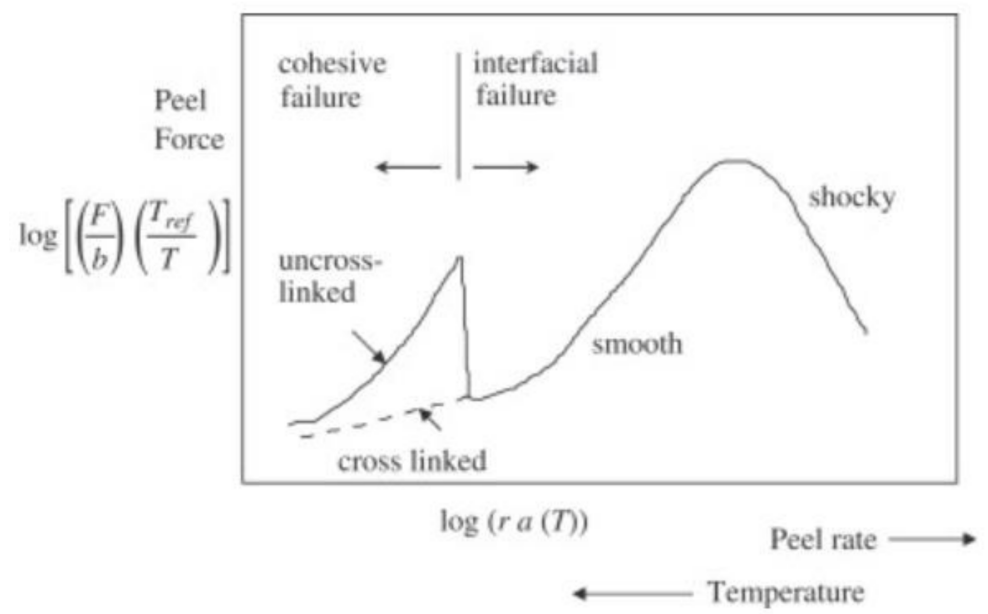

Figure 19. General shape of peel force master curve for peel rate and temperature dependence (reproduced from [48] with permission from Elsevier®, license number 5226440524626, January 2022).

By visual inspection, such an outcome can be easily identified. At low rates, the adhesive separates cleanly from the substrates (as in the present study), while in the other case visible PSA traces remain on the glass support. Accordingly, in cohesive failure, fracture occurs between the interface of adhesive and adherent, and tend to be more sensitive to the variation of PSA parameters, such as pressure, temperature, etc $[48,49]$.

\subsection{Ageing}

To assess the effect of ageing on the fracture energy parameter $(G)$, comparisons of experimental and numerical results are obtained as described in Section 6.1

It is worth noting, for the selected charts in Figure 20, the rather close correlation between the experimental peel curves and the corresponding FE numerical estimates, under different ageing conditions.

The values of the mean fracture energy parameters obtained at various heating temperatures and exposure times are also summarized in Figures 21 and 22, both in experimental and numerical terms. In both, the trend of the improvement in adhesive performance already described in Figure 19 is confirmed.

Generally, the peel tests showed that the adhesive fracture energy values, according to the theoretical approach based on the Kinloch method, resulted in higher predictions based on FE simulations. Although the results in terms of (peel force-displacement) curves are quite similar, the energy parameters differ due to the basic assumptions on which the FE model was built. Since there were insufficient data for modelling behaviour in the three directions, the components of the traction vector were assumed to be equal. In addition, the influence of the Mode II component which represents the work carried out by shear stress in the sliding direction was neglected.

Moreover, in both cases, with $T=50{ }^{\circ} \mathrm{C}$, an upward trend can be noted, while with $T=70{ }^{\circ} \mathrm{C}, \mathrm{G}_{a}$ can be seen to increase in a range of up to $24 \mathrm{~h}$, resulting in the degradation of adhesion properties, as shown in Figures 21 and 22. 


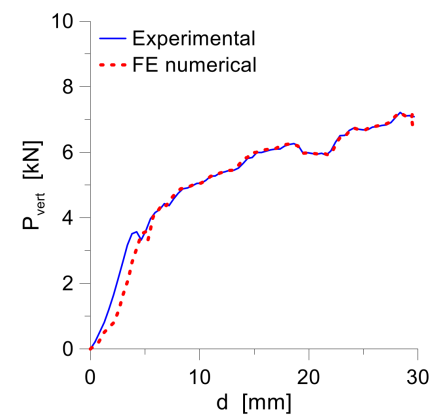

$\# 5(t=3 \mathrm{~h})$

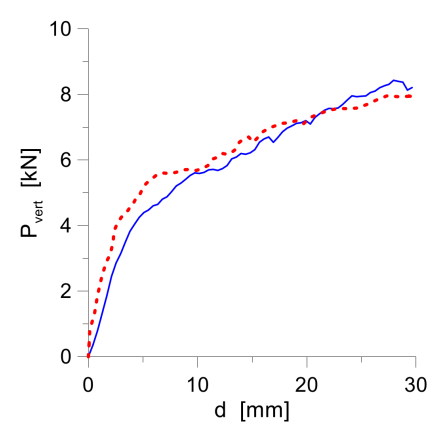

$\# 15(\mathrm{t}=72 \mathrm{~h})$

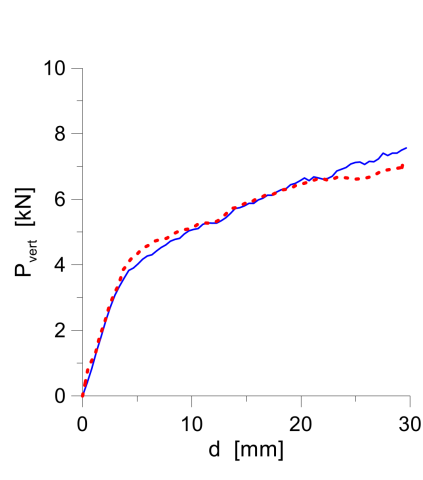

$\# 10(\mathrm{t}=24 \mathrm{~h})$

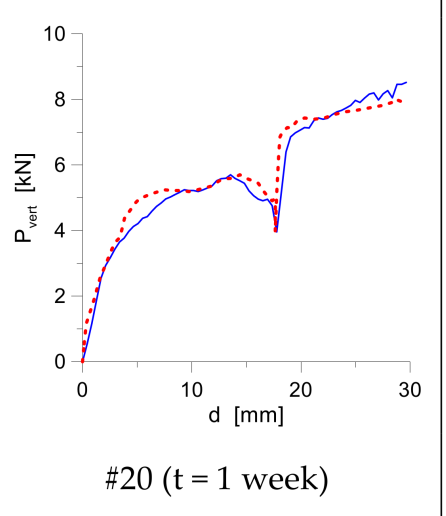

(a)
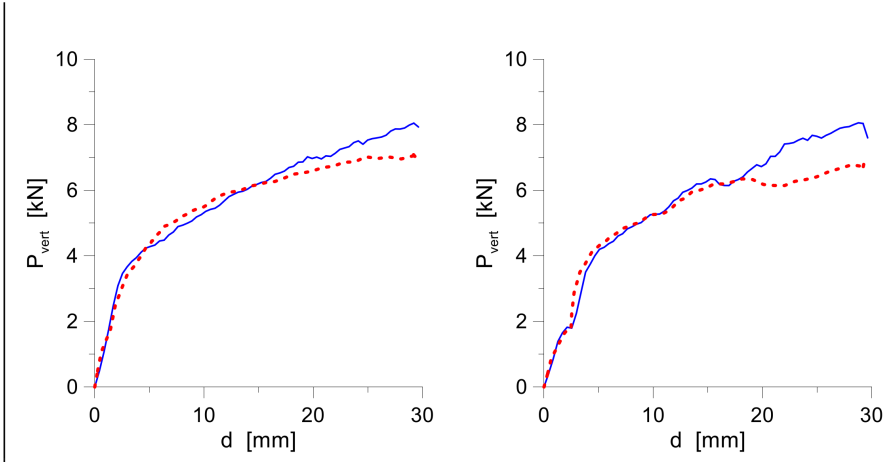

$\# 25(\mathrm{t}=3 \mathrm{~h})$

$\# 30(t=24 \mathrm{~h})$

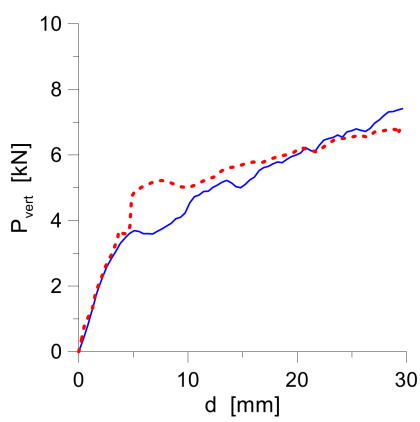

$\# 35(t=72 \mathrm{~h})$

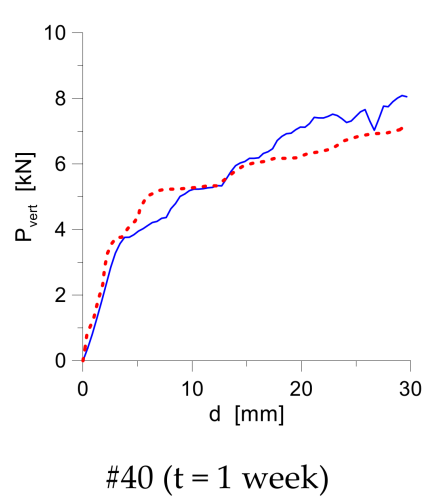

(b)

Figure 20. Comparison between selected FE numerical and experimental peel curves at ageing temperatures equal to (a) $50{ }^{\circ} \mathrm{C}(\mathbf{b}) 70^{\circ} \mathrm{C}$.

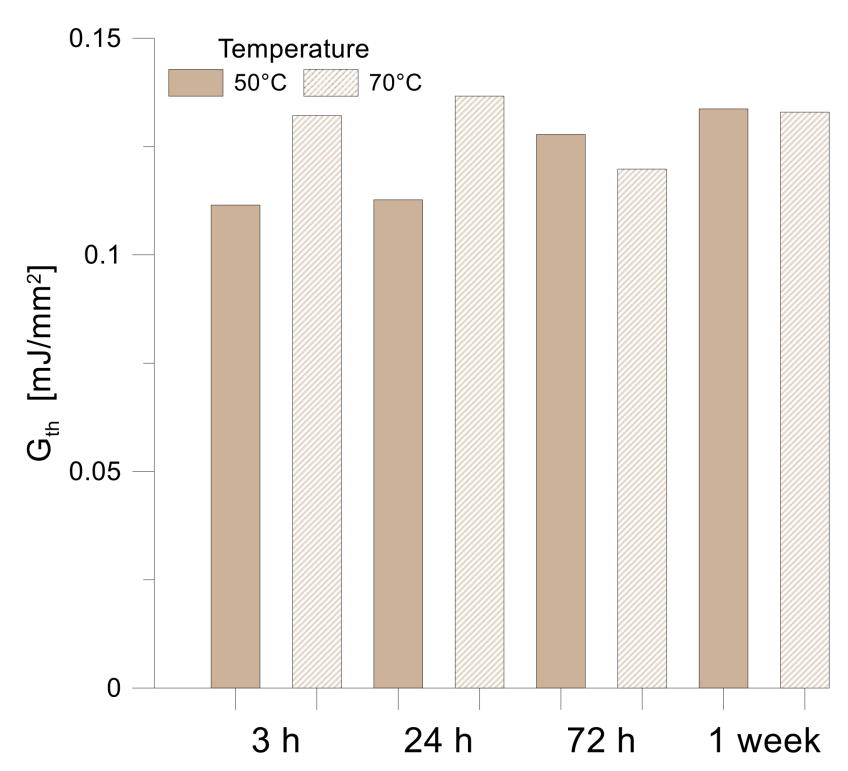

(a)

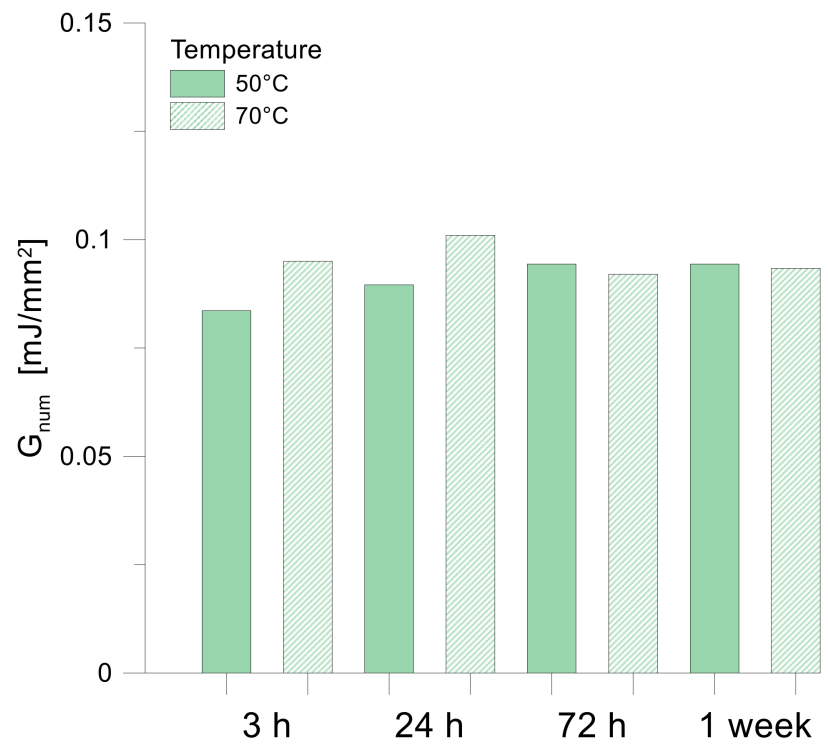

(b)

Figure 21. Fracture energy as a function of ageing time, as obtained by (a) experimental and theoretical approach or (b) FE numerical method. 


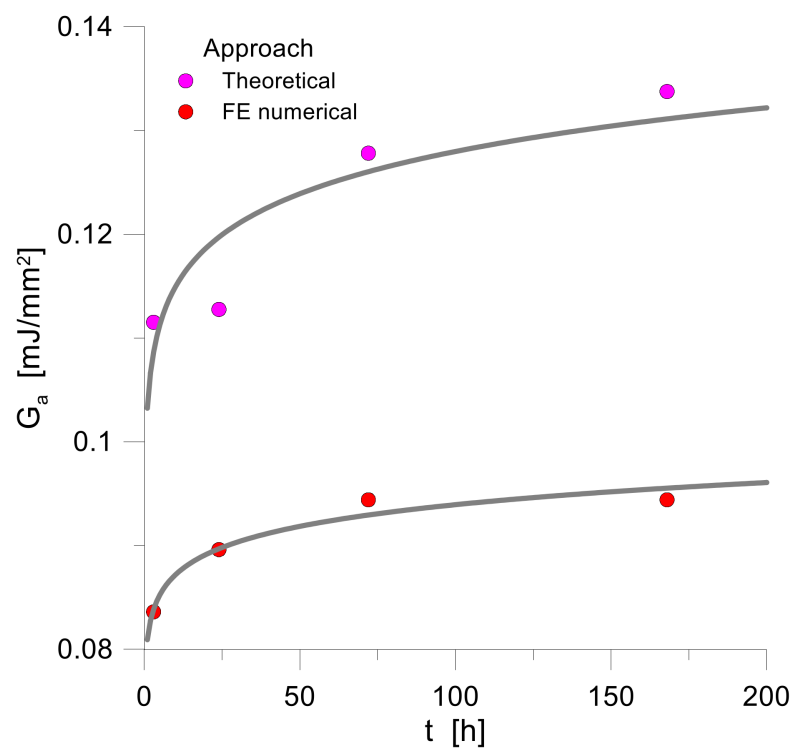

(a)

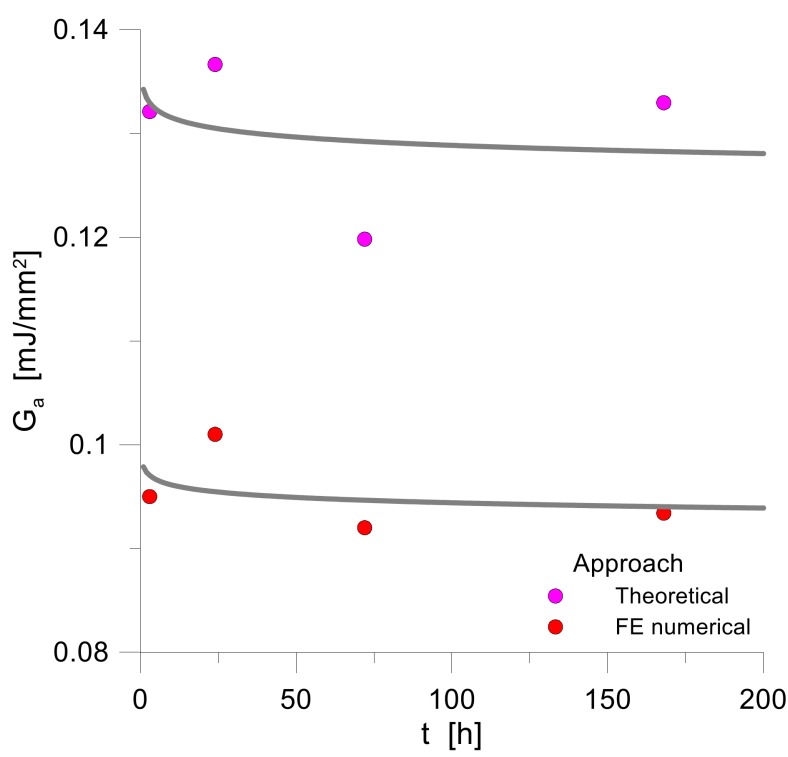

(b)

Figure 22. Fracture energy as a function of ageing time at (a) $50^{\circ} \mathrm{C}$ or (b) $70{ }^{\circ} \mathrm{C}$, as obtained by experimental and theoretical approach or FE numerical method. In evidence, the fitting curves of average data.

As shown, increasing temperature had essentially the same effect on $G$ peel velocity in the case of $50{ }^{\circ} \mathrm{C}$. In contrary, the trend appears reversed at $70{ }^{\circ} \mathrm{C}$, given that it is close to the glass transition temperature $\left(T_{g}\right)$ that was preliminary obtained by DSC for the investigated ASF samples. Finally, the inverse detection of fracture energy parameters carried out with the support of calibrated FE numerical models generally resulted in partial underestimation of experimental parameters, with an error in the order of $\approx 25 \%$, as can be seen in Figure 22 for both imposed ageing temperatures.

\section{Conclusions}

In this paper, the mechanical behaviour of unaged and aged multi-layer anti-shatter films (ASFs) for safety covers in structural glass applications was investigated based on experimental methods, theoretical approaches and Finite Element (FE) numerical modelling techniques. For a total of 52 small-scale samples, an alternative peeling setup was taken into account under various artificial ageing configurations.

Generally, both temperature and peel rate are known to significantly affect the mechanical behaviour of polymers. In this regard, the ASF-bonded glass specimens were grouped by peel rate ( 3 configurations) and time/temperature of ageing condition ( 8 in total). The relations between fracture energy and ageing conditions were investigated and it was observed that, as the period of heating exposure increases, it tends to obtain a higher value of $G_{a}$ when the ageing temperature is sufficiently below the glass transition temperature. Furthermore, since the PSA model calibrated under the mode I failure showed a rather good agreement with the experimental experiences, it can be concluded that reliable FE numerical models of ASFs and ASF-bonded glass elements can be built. However, the limitation of the use of the Cohesive Zone Modelling (CZM) technique lies in the fact that it cannot fully seize the phenomena of crack propagation in the adhesive layer, and, for this reason, the calibration analyses should be carried out considering separately the detailing of each specimen. The experimental observations in fact highlighted that the ASF properties vary from specimen to specimen, and the variability was assessed by considering numerical and experimental outcomes on similar groups of samples/ageing conditions (5 per sample). 
Generally, the peel tests showed that the adhesive fracture energy, as obtained according to the theoretical approach based on the Kinloch method, resulted in higher values than calibrated FE simulations. Moreover, in both cases, a certain upward trend of fracture parameters was observed for $T=50{ }^{\circ} \mathrm{C}$, while an increasing $G_{a}$ trend was observed for $T=70{ }^{\circ} \mathrm{C}$ in the range up to $24 \mathrm{~h}$ of heating exposure, and then followed by a degradation of adhesion properties.

Despite this, key parameters were properly detected to support critical design considerations, as well as to support the implementation of realistic FE numerical models for the study of ASF-bonded glass elements.

In the future, a possible extension of the present study should examine the cyclic response of PET-film samples, so as to capture experimentally and numerically a realistic measure of dissipation capacity in ASF-bonded glass elements, due to plastic deformations with a variable root rotation.

Similarly, the present outcomes will support an extension of the experimental and numerical analysis to the assessment of the dynamic performance of ASF-bonded glass elements in the post-breakage stage, or the impact response of full-size ASF-bonded glass members for structural applications in buildings.

Author Contributions: Conceptualization; methodology; writing — original draft preparation; writingreview and editing; visualization, S.M., L.C, C.B. Investigation; data curation; formal analysis, S.M., L.C. Supervision; project administration; funding acquisition, C.B. All authors have read and agreed to the published version of the manuscript.

Funding: This research was partially funded by University of Trieste, “Microgrants 2020" grant.

Institutional Review Board Statement: Not applicable.

Informed Consent Statement: Not applicable.

Data Availability Statement: Supporting data will be made available upon request.

Acknowledgments: Chiara Schmid (University of Trieste) is gratefully acknowledged for the support during the experimental investigation. This research study was financially supported by University of Trieste ("Microgrants 2020" grant). The ongoing EU COST Action CA18120 "CertBond" is also acknowledged for facilitating research networking and discussion of present topic by authors with international experts. Finally, Seretti Vetroarchitetture is acknowledged for providing glass samples.

Conflicts of Interest: The authors declare no conflict of interest.

\section{References}

1. Matias, Á.A.; Lima, M.S.; Pereira, J.; Pereira, P.; Barros, R.; Coelho, J.F.; Serra, A.C. Use of recycled polypropylene/poly (ethylene terephthalate) blends to manufacture water pipes: An industrial scale study. Waste Manag. 2020, 101, 250-258. [CrossRef] [PubMed]

2. Simpson, D.M.; Vaughan, G.A. Ethylene polymers, LLDPE. Encycl. Polym. Sci. Technol. 2002, 2.

3. Behr, R.A.; Belarbi, A.; Brown, A.T. Seismic performance of architectural glass in a storefront wall system. Earthq. Spectra 1995, 11, 367-391. [CrossRef]

4. Baird, A.; Palermo, A.; Pampanin, S. Facade damage assessment of multi-storey buildings in the 2011 Christchurch earthquake. Bull. N. Z. Soc. Earthq. Eng. 2011, 44, 368-376. [CrossRef]

5. Martins, L.; Delgado, R.; Camposinhos, R.; Silva, T. Seismic Behaviour of Point Supported Glass Panels. In Challenging Glass 3: Conference on Architectural and Structural Applications of Glass; Faculty of Civil Engineering and Geosciences, Delft University of Technology: Delft, The Netherlands, 2012; p. 281.

6. Koper, K.D.; Wallace, T.C.; Hollnack, D. Seismic analysis of the 7 August 1998 truck-bomb blast at the American embassy in Nairobi, Kenya. Seism. Res. Lett. 1999, 70, 512-521. [CrossRef]

7. Van Dam, S.; Pelfrene, J.; De Pauw, S.; Van Paepegem, W. Experimental study on the dynamic behaviour of glass fitted with safety window film with a small-scale drop weight set-up. Int. J. Impact Eng. 2014, 73, 101-111. [CrossRef]

8. Figuli, L.; Papan, D.; Papanova, S.; Bedon, C. Experimental mechanical analysis of traditional in-service glass windows subjected to dynamic tests and hard body impact. Smart Struct. Syst. 2021, 27, 365-378.

9. Caterino, N.; Del Zoppo, M.; Maddaloni, G.; Bonati, A.; Cavanna, G.; Occhiuzzi, A. Seismic assessment and finite element modelling of glazed curtain walls. Struct. Eng. Mech. 2017, 61, 77-90. [CrossRef] 
10. Brueggeman, J.L.; Behr, R.A.; Wulfert, H.; Memari, A.M.; Kremer, P.A. Dynamic racking performance of an earthquake-isolated curtain wall system. Earthq. Spectra 2000, 16, 735-756. [CrossRef]

11. Bárány, T.; Ronkay, F.; Karger-Kocsis, J.; Czigány, T. In-plane and out-of-plane fracture toughness of physically aged polyesters as assessed by the essential work of fracture (EWF) method. Int. J. Fract. 2005, 135, 251-265. [CrossRef]

12. Thurston, S.J.; King, A.B. Two-Directional Cyclic Racking of Corner Curtain Wall Glazing; Building Research Association of New Zealand: Wellington, New Zealand, 1992.

13. Hutchinson, T.C.; Zhang, J.; Eva, C. Development of a drift protocol for seismic performance evaluation considering a damage index concept. Earthq. Spectra 2011, 27, 1049-1076. [CrossRef]

14. Memari, A.M.; Behr, R.A.; Kremer, P.A. Dynamic racking crescendo tests on architectural glass fitted with anchored pet film. J. Archit. Eng. 2004, 10, 5-14. [CrossRef]

15. Centre for the Protection of National Infrastructure. Guidance Note: Peel Adhesion Testing and Assessment of Anti-Shatter Film (ASF); Centre for the Protection of National Infrastructure: London, UK, 2013.

16. Gent, A.N.; Hamed, G.R. Peel Mechanics. J. Adhes. 1975, 7, 91-95. [CrossRef]

17. Kaelble, D.H. Theory and analysis of peel adhesion: Mechanisms and mechanics. Trans. Soc. Rheol. 1959, 3, 161-180. [CrossRef]

18. Kaelble, D.H. Theory and analysis of peel adhesion: Bond stresses and distributions. Trans. Soc. Rheol. 1960, 4, 45-73. [CrossRef]

19. Kaelble, D.H. Peel adhesion: Micro-fracture mechanics of interfacial unbonding of Polymers. Trans. Soc. Rheol. 1965, 9, 125-163. [CrossRef]

20. Kaelble, D.H. Theory and Analysis of peel adhesion: Rate-temperature dependence of viscoelastic interlayers. J. Colloid Sci. 1964, 19, 413-424. [CrossRef]

21. Gent, A.N.; Petrich, R.P. Adhesion of viscoelastic materials to rigid substrates. Proc. R. Soc. A 1969, 310, $433-448$.

22. Kinloch, A.J.; Lau, C.C.; Williams, J.G. The peeling of flexible laminates. Int. J. Fract. 1994, 66, 45-70. [CrossRef]

23. Kinloch, A.J. Adhesive in engineering. Proc. Inst. Mech. Eng. Part G J. Aerosp. Eng. 1997, 211, 307-335. [CrossRef]

24. Anderson, T.L. Fracture Mechanics: Fundamentals and Applications, 3rd ed.; CRC press: Boca Raton, FL, USA, 2005.

25. Kinloch, A.J. The science of adhesion. J. Mater. Sci. 1980, 15, 2141-2166. [CrossRef]

26. IC_Peel. Adhesion, Adhesives and Composites Group, Imperial College, London, UK. Available online: http://www3.imperial. ac.uk/meadhesion/estprotocols/peel (accessed on 12 January 2022).

27. ASTM D882-02. Standard Test Method for Tensile Properties of Thin Plastic Sheeting. p. 9. Available online: https://doi.org/10.1520/ D0882-02 (accessed on 12 January 2022).

28. Bedon, C.; Mattei, S. Multistep Experimental Calibration of Mechanical Parameters for Modelling Multilayer Antishatter Safety Films in Structural Glass Protection. Math. Probl. Eng. 2021, 2021, 14. [CrossRef]

29. Simulia. ABAQUS v. 6.12 Computer Software and Online Documentation; Dassault Systems: Providence, RI, USA, 2017.

30. GRANTA Design. CES Selector Software Materials Data Set, 2012. In Polymer Data Handbook, 2nd ed.; Oxford Press: Oxford, UK, 1999.

31. JRC Scientific and Policy Reports. Fibre Labelling Polytrimethylene Terephthalate-PTT-DuPont; European Union: Luxembourg, 2013; Available online: https:/ / doi.org/10.2788/82737 (accessed on 12 January 2022).

32. Socrates, G. Infrared and Raman Characteristic Group Frequencies: Tables and Charts; John Wiley \& Sons: Hoboken, NJ, USA, 2004.

33. Aflori, M. Plasma processing of surfaces and particles. In Proceedings of the 28th International Conference on Phenomena in Ionized Gases (ICPIG), Prague, Czech Republic, 15-20 July 2007.

34. Arkhireyeva, A.; Hashemi, S. Effect of temperature on fracture properties of an amorphous poly(ethylene terephthalate) (PET) film. J. Mater. Sci. Technol. 2002, 37, 3675-3683.

35. Funabashi, M.; Ninomiya, F.; Oishi, A.; Ouchi, A.; Hagihara, H.; Suda, H.; Kunioka, M. Poly (ethylene terephthalate) Film Using Xenon Lamp with Heating System. J. Polym. 2016, 2016, 8547524.

36. Gupta, S.; Dixit, M.; Sharma, K.; Saxena, N.S. Mechanical study of metallized polyethylene terephthalate (PET) films. Surf. Coat. Technol. 2009, 204, 661-666. [CrossRef]

37. Gohil, R.M. Morphology-Property Relationship in Oriented PET Films: Microstrudural Reorganization during Heat Treatment. J. Appl. Polym. Sci. 1994, 52, 925-944. [CrossRef]

38. Kanuga, K. Degradation of polyester film exposed to acerated indoor damp heat aging. In Conference Record of the IEEE Photovoltaic Specialists Conference; IEEE: Piscataway, NJ, USA, 2011; pp. 96-100.

39. Mohandesi, J.A.; Refahi, A.; Meresht, E.S.; Berenji, S. Effect of temperature and particle weight fraction on mechanical and micromechanical properties of sand-polyethylene terephthalate composites: A laboratory and discrete element method study. Compos. Part B 2011, 42, 1461-1467. [CrossRef]

40. Oreski, G.; Wallner, G.M. Delamination behaviour of multi-layer films for PV encapsulation. Sol. Energy Mater. Sol. Cells 2005, 89, 139-151. [CrossRef]

41. ASTM D1876-08(2015)e1—Standard Test Method for Peel Resistance of Adhesives (T-Peel Test); ASTM International: West Conshohocken, PA, USA, 2015.

42. ASTM D903-98(2017)—Standard Test Method for Peel or Stripping Strength of Adhesive Bonds; ASTM International: West Conshohocken, PA, USA, 2017.

43. ISO 11339:2010_Adhesives_-T-Peel Test for Flexible-to-Flexible Bonded Assemblies; ASTM International: West Conshohocken, PA, USA, 2010 
44. Kovalchick, C.; Molinari, A.; Ravichandran, G. Rate Dependent Adhesion Energy and Nonsteady Peeling of Inextensible Tapes. J. Appl. Mech. 2014, 81, 041016. [CrossRef]

45. Musto, M.; Alfano, G. A novel rate-dependent cohesive-zone model combining damage and visco-elasticity. Comput. Struct. 2013, 118, 126-133. [CrossRef]

46. Musto, M.; Alfano, G. A fractional rate-dependent cohesive zone model. Int. J. Numer. Methods Eng. 2015, 103, 313-341. [CrossRef]

47. ISO 9142:2003-Adhesives — Guide to the Selection of Standard Laboratory Ageing Conditions for Testing Bonded Joints; ASTM International: West Conshohocken, PA, USA, 2003.

48. McGuiggan, P.M.; Chiche, A.; Filliben, J.J.; Yarusso, D.J. Peel of an adhesive tape from a temperature-gradient surface. Int. J. Adhes. Adhes. 2008, 28, 185. [CrossRef]

49. Yarusso, D.J. Effect of Rheology on PSA Performance. In Chapter 13 in 'The Mechanics of Adhesion'; Elsevier: Amsterdam, The Netherlands, 2002; pp. 499-533. ISBN 0444511407. 